\title{
The Rise of the Machines: Automation, Horizontal Innovation and Income Inequality
}

\author{
David Hémous (INSEAD and CEPR) and Morten Olsen (IESE)
}

September 2013

Very Preliminary and Incomplete

\begin{abstract}
We construct an endogenous growth model of directed technical change with automation - the introduction of machines which replace low-skill labor and complement high-skill labor - and horizontal innovation - the introduction of new products, which increases demand for both types of labor. Machines are produced with the same technology as the consumption good. The level of technology in the economy is characterized by the number of products and the share of these that are automated. For general processes of technology, we demonstrate that although low-skill wages can drop during periods of increasing automation intensity the asymptotic growth rate is positive, though lower than that of the economy. We then endogenize the evolution of technology and derive an asymptotic steady state. Through numerical simulations, we show that the transitional path follows three phases. First, wages are low such that few machines are used and low-skill wages keep pace with the growth rate of the economy. Then, as wages grow the share of automated products increases and the economy substitutes towards the use of machines which depresses the growth rate of low-skill wages, potentially to negative. Finally, as the economy reaches steady state the share of automated products is constant and the relative growth rate of low-skill wages picks up though it remains lower than that of the economy. We extend the model to include middle-skill workers and demonstrate that the model endogenously captures two important characteristics of the U.S. income distribution over the past 50 years: initially a monotone dispersion of the income distribution, and thereafter a wage growth polarization, in which middle-skill workers experience the lowest wage growth. Finally, in an extension we allow machines to be produced with a different technology than the consumption good. This allows for faster productivity growth for machines which can potentially lead to permanently negative growth of low-skill wages.
\end{abstract}

JEL: E23, E25, O33, O31, O41

KEYWORDS: Capital-skill complementarity, income inequality, automation, horizontal innovation, wage polarization 


\section{Introduction}

Will technological progress benefit all workers, or will some become superfluous as the Luddites feared in XIX ${ }^{\text {th }}$ England? Economists have long dismissed this concern, emphasizing that new jobs are created to replace those lost to technology. Yet, that argument is mostly absent from the theoretical literature on technology and income distribution, which has largely ignored labor-replacing innovation by focusing on skilled- versus unskilled- labor augmenting technical change (Acemoglu and Autor, 2011). In the face of increasing income inequality and a declining labor share of output, the concern is receiving renewed interest (Brynjolfsson and McAfee, 2011 and Kotlikoff and Sachs, 2013). In fact, mounting empirical evidence shows that much technological development takes the form of labor-saving automation of production processes, mostly replacing low-skill workers (Autor, Levy, Murnane, 2003). ${ }^{1}$ In this paper, we formalize the economists' popular argument by introducing a labor-replacing automation technology into an expanding variety growth model, and we analyze when technological progress reduces the welfare of some workers. In addition, our model is consistent with several features of the evolution of the income distribution in the last 40 years, including a growing inequality between high-skill and low-skill workers' income, wage polarization and a moderate decline in the labor share.

We consider an economy populated by low-skill and high-skill workers, where a final good is produced by combining a set of intermediate inputs. These are produced by two types of firms. Non-automated firms must rely on both types of labor, whereas automated firms can replace low-skill workers with machines produced from the final good. Automation of production by existing firms increases the overall productive capability of the economy, but reduces the relative demand for low-skill workers. This contrasts with technological development that introduces new products which also improves the economy's economic productivity but increases the demand for both types of labor. High-skill workers always benefit from either, but low-skill workers may, but need not, lose from automation. Though low-skill workers may lose temporarily from automation, we show that for very general processes of technological development, their welfare must grow asymptotically, albeit at a lower rate than that of high-skill workers. We then endogenize technological development by assuming that new products start non-automated and by letting both types of technological progress be the result of deliberate innovation. We show that the incentives to automate depends on the level of low-skill wages. This introduces a structural shift in the economy, in which the low initial wages imply little incentive to automate such that low-skill wages grow at pace with the economy. As the economy grows so do low-skill wages and the incentive to automate increases. The growth rate of the economy increasingly relies on automation and income inequality continuously rises. In an extension, we introduce middle-skill workers and show that the model can generate wage polarization.

The model features a two-dimensional level of technology: the measure of existing intermediate inputs and the fraction of these that can be produced by an automated process. Both increase the productive capabilities of the economy, but by allowing for replacement of low-skill workers, automation can reduce their absolute pay. For most of the analysis, we assume that the machines are produced competitively one-for-one with the final good, which, importantly,

\footnotetext{
${ }^{1}$ Autor, Katz and Kearney (2006) argue that in the 1990s it was predominantly workers in the middle of the income distribution, performing 'cognitive routine tasks' that were replaced, a tendency they label 'job polarization'.
} 
ties the price of machines to that of the consumption good. This makes the absolute level of low-skill wages an important economic variable, not just as a measure of the welfare of low-skill workers, but also as their cost disadvantage with machines. High low-skill wages both encourage a substitution away from low-skill workers to machines for automated firms and imply a shift of market shares towards automated firms. As a result, higher low-skill wages are associated with a higher skill premium. Initially, we consider general exogenous technological processes with continuous growth in the measure of inputs. We show that in periods with increasing automation low-skill wages can drop, although as long as there is not economy-wide perfect substitution between low-skill workers and machines, low-skill wages must grow asymptotically as well. To see why, note that a growing use of machines combined with a fixed stock of lowskill labor must increase the relative price of low-skill workers compared with machines. When machines are produced with the same general technology as the consumption good, this relative price equals the real wage of low-skill workers and their welfare must increase asymptotically. In particular, economy-wide imperfect substitution between low-skill and machines is obtained if a positive fraction of the new products does not become automated immediately after entry, even if low-skill workers and machines are perfect substitutes in the production process of automated firms. Hence, as in the 'economists' popular argument' above, even if low-skill workers are fully replaced in the production of existing products, the creation of new ones ensure that their income keeps increasing.

We proceed to analyze specific endogenous technological processes where both automation and the introduction of new goods are the result of deliberate investment in research. As in Romer (1990), a fringe of potential entrepreneurs invest to introduce new products which are initially produced by non-automated technological processes. Once they have created a new product they can conduct a second innovation as in Aghion and Howitt (1996), which here takes the form of automation. This introduces another margin of substitution between machines and low-skill workers: the higher are the low-skill wages the higher is the incentive to automate to acquire the ability to use machines. We allow for an externality, where the stock of automated products may positively impact the productivity of the automation innovation technology. We characterize the asymptotic steady state and show that improvements in the technology for automation innovation will increase horizontal innovation, implying a higher asymptotic wage, even for low-skill workers.

We then employ simulation methods to study the model's transitional dynamics. These can be thought of as occurring in three phases. First, with low levels of technology, low-skill wages are low and there is little automation. During this phase, there is little incentive to automate and the growth rate of low-skill wages mirrors that of the overall economy implying that factor shares of both low- and high-skill workers remains relatively constant. As low-skill wages and the stock of automated varieties increase, the incentive to invest in automation increases. This brings the economy into the next phase in which the fraction of automated products is increasing, putting downward pressure on low-skill wages. During this transitional phase the relative growth rate of low-skill workers is the lowest and potentially negative. Finally, once the fraction of automated products approaches its steady state level, the economy enters its third phase. The share of automated products is no longer increasing and low-skill wage growth must be positive, although lower than that of the overall economy. The factor share of low-skill workers continues to decrease. The factor share of high-skill workers increases, though labor's overall factor share decreases modestly, consistent with recent evidence in Rodriguez 
and Jayadev (2013), Karabarbounis and Neiman (2013) and Piketty and Zucman (2013). We conduct a growth decomposition and demonstrate how the growth in the economy transitions from being driven solely by the entrance of new products to relying on both types of innovation.

We show that when considering the full transitional path, changes to the productivity of the automation technology have ambiguous effects on the welfare of low-skill workers. Though, more productive automation technology unambiguously increases the use of machines in the economy and reduces low-skill workers share of output, it also encourages faster entry and increases the overall growth rate of the economy. As noted above, a more productive automation technology guarantees higher asymptotic wages through a higher growth rate of the economy, but in our simulations, we show that it can reduce low-skill wages during the second phase of accelerating automation.

Recent empirical work has increasingly found that workers in the middle of the income distribution are most adversely affected by technological progress. To address this, we extend the model to include middle-skill workers as a separate skill-group. Firms either rely on lowskill workers or middle-skill workers (but not both) and the two skill-groups are symmetric except that automating to replace middle-skill workers is more costly. This means that the automation of low-skill workers will happen first, with a delayed automation process for middleskill workers. We show that this difference can reproduce important trends in the United States income distribution as described in Autor, Katz and Kearney (2006): in a first period there is a uniform dispersion of the income distribution, as low-skill workers' task are rapidly automated but middle-skill tasks are not; while in the second period there is wage polarization: low-skill workers' share of automated products is close to steady-state, and middle-skill tasks are more rapidly automated.

The baseline model restricts the production technology of consumption goods and machines to be identical and permanently binds each type of worker to a category even as wage dispersion grows. In extensions, we relax each of these assumptions in turn. We allow the production of machines to rely more heavily on the use of machines as inputs than the production of the consumption good, which endogenously delivers faster growth in the production of machines and a resulting decreasing real price. This extension allows for both a productivity effect, as more machines increases the productive capability of the economy, and a substitution effect as the cheaper price of machines further increases their cost-advantage over low-skill workers. The elasticity of substitution between varieties crucially determines the relative size of these effects, with a higher value both reducing the gain in productivity from new products and ensuring a larger shift in market share from non-automated to automated firms. As a result, for sufficiently high elasticity of substitution, the asymptotic growth rate of low-skill real wages is negative. In a second extension, the workforce consists of a mass of workers each endowed with innate heterogeneous abilities to perform low-skill or high-skill tasks. Diverging returns to the two, endogenously results in a shift from low-skill to high-skill employment. Those switching will benefit from the higher growth rate of high-skill wages, and the gradual reduction in the stock of low-skill labor implies that low-skill wages grow at a higher relative rate.

Income inequality between skill groups has been steadily increasing in developed countries (particularly in the US) since the 1970's, even though education has increased the relative supply of skilled workers. Following the pioneering work of Tinbergen $(1974,1975)$, a large literature has turned to skill-biased technical change (SBTC) as a possible cause for this trend (see Hornstein, Krusell and Violante, 2005, for a more complete literature review). One can 
roughly categorize theoretical papers into one of three strands. The first strand emphasizes the Nelson and Phelps (1966) hypothesis that more skilled workers are better able to adapt to technological change, in which case a technological revolution (like the IT revolution) increases the relative demand for skilled workers and increases income inequality. Several papers have formalized this idea (including Aghion and Howitt, 1997, Lloyd-Ellis, 1999, Caselli, 1999, Galor and Moav, 2000 and Aghion, Howitt and Violante, 2002). However, such theories mostly explain transitory increase in inequality whereas inequality has been increasing for decades. Our model, on the contrary, introduces a mechanism that creates permanent (and widening) inequality.

A second strand sees the complementarity between capital and skill as the source for the increase in the skill premium. Krusell, Ohanian, Ríos-Rull, and Violante (2000) are the first to formalize this idea; they develop a framework where capital equipment and high-skill labor are allowed to be complementary. To this they add the empirically observed decline in the price of capital equipment (relative to the consumption good), and show that their model can then account for most of the variations in the skill premium. Our model shares features with their framework: machines, which here depreciate immediately but play an analogous role to capital in their model, are more complementary with skilled labor than with unskilled labor, and the decrease in the price of machines relative to the price of other inputs leads to an increase in the relative demand for skilled labor over unskilled labor. However, we endogenize the evolution of technological progress. ${ }^{2}$

Finally, the third branch of the literature emphasizes the role of factor specific technical change. This framework, originally presented by Katz and Murphy (1992) considers technology to be either high-skill labor or low-skill labor-augmenting and employs a relative supply and demand framework of these two skill groups - typically college and non-college graduates to infer the extent of skill-biased technical change from changes in the relative labor supply and the skill-premium. This 'canonical model', as labeled by Acemoglu and Autor (2011), has been widely used in empirical work. On the theory side, it has led to a large literature on directed technical change (most notably Acemoglu, 1998, 2002 and 2007), which endogenizes the bias of technical change. In particular, it shows that an increase in the supply of high-skill workers may foster skill biased technical change and increase the skill premium. This model delivers important insights about inequality and technical change, but it has no role for laborreplacing technology (a point emphasized in Acemoglu and Autor, 2011). In addition, even though income inequality varies, neither high-skill nor low-skill wages can decrease in absolute terms, and their asymptotic growth rate must be the same. The present model is also a directed technical change framework as economic incentives determinate whether technical change takes the form of horizontal innovation or automation (and is therefore closer to Aghion and Howitt, 1996), but, it deviates from the assumption of factor-augmenting technologies and explicitly allows for labor-replacing automation, generating the possibility for (temporary) absolute losses for low-skill workers, and permanently increasing income inequality.

\footnotetext{
${ }^{2}$ An additional difference is that we do not need a decrease in the price of machines relative to the consumption good to generate this pattern. This is because in our set-up, at given factor prices, horizontal innovation is Harrod-Neutral, and therefore reduces the price of machines relative to labor. In their set-up, technological progress is either labor augmenting or increases the productivity of the sector producing the investment good. With only labor-augmenting technological change the price of capital would not decrease relative to the price of effective units of labor. Nonetheless, in section 7.1, we allow for different production functions for the consumption and investment goods, which translate into a decreasing price for machines relative to the consumption good.
} 
In addition to the theoretical foundations for SBTC, an extensive literature examines its empirical importance and in particular its role in the marked increase in income inequality in the US and other advanced countries since the early 1980s. ${ }^{3}$ At the firm and industry level, there is compelling evidence of a strong correlation between the adoption of automation technologies and the increased reliance on skills. ${ }^{4}$ Using the canonical model Goldin and Katz (2008) find that in the US as a whole technical change has been skill-biased throughout the 20th century (with the skill-bias being the premium of a high school graduate in the early part of the century). Further, changes in the supply of skilled labor coupled with a linear trend in the bias of technological change fit the data remarkably well over the last 50 years, though the data suggests a slowdown in SBTC from the mid 1990s onwards. Card and DiNardo (2002) and Lemieux (2006) consider this slow-down in income inequality growth in the presence of continued advances in computer technology as undermining for the usefulness of the concept of SBTC in explaining observed patterns in income inequality. We do not equate SBTC with skill-augmenting technological change, but instead model it explicitly as the automation of production processes. This puts the relative stock of automated products central in explaining the skill-premium, but does not create a one-to-one relationship between (the flow of) automation intensity and automation's impact on the skill-premium. Hence, in our framework an increasing intensity of automation is perfectly consistent with a slowing growth in income inequality.

Autor, Levy, Murnane (2003) and the literature following (Autor, Katz, and Kearney, 2006, 2008 and Autor and Dorn, 2013) suggest a different answer to the apparent slowdown of the skill-bias of technical change. They argue that a closer look at the income distribution is called for and show that whereas income inequality has continued to increase above the median, there has been a reversal below the median. They argue that the (routine) tasks performed by many middle-skill workers - storing, processing and retrieving information - are more easily done by computers than those performed by low-skill workers, now predominantly working in service occupations. This 'wage polarization' has been accompanied by a 'job polarization' as employment has followed the same pattern of decreasing employment in middle-skill occupations. ${ }^{5}$ Acemoglu and Autor (2011) argue that a task-based model where technological progress explicitly allows the replacement of one input, say labor, by another, say capital, in the production of some tasks provides a better explanation for wage and job polarization than the canonical model (and in addition allows for a decrease in the absolute level of wages). In our theory, automation similarly replaces labor with machines in the production of some goods. Its advantage over the task framework is that when we consider the extension with both low-skill and middle-skill workers, it provides a unified explanation for the relative decline of middle-skill wages since the mid-1980s and the relative decline of low-skill wages in the period before. If automating the tasks performed by low-skill workers is easier (cheaper) than for those performed by middle-skill workers, the lion's share of the increase in the fraction of automated product

\footnotetext{
${ }^{3}$ The extent to which patterns in income inequality over the last few years are the result of the financial crisis or underlying structural changes is a topic of ongoing debate and research. For this reason, we restrict ourselves to changes in income inequality prior to 2008.

${ }^{4}$ Autor, Katz, and Krueger (1998), Autor, Levy, and Murnane (2003), Doms, Dunne and Troske (1997), Bartel, Ichniowski, and Shaw (2007).

${ }^{5}$ This phenomenon has also been observed and associated with the automation of routine tasks in Europe (Spitz-Oener, 2006, Goos and Manning, 2007, and Goos, Manning and Salomons, 2009). Another explanation for polarization stems from the consumption side and relates the high growth rate of wages for the least-skilled workers with an increase in the demand for services from the most-skilled - and richest - workers, see Mazzolari and Ragusa (2013) and Barany and Siegel (2013).
} 
will happen later for middle-skill workers than for low-skill workers, and their respective periods of lower wage growth will be sequential: The automation of the factory floors in the middle of the century - primarily replacing low-skill workers - and the introduction of computers in the latter third — primarily replacing middle-skill workers. ${ }^{6}$

Section 2 introduces the model and solves for equilibrium wages. Section 3 introduces exogenous technological processes and derives the asymptotic growth rates of wages. In Section 4 we endogenize the technological processes and solve for the steady state and Section 5 simulates the transitional dynamics. Section 6 extends the model to include middle-skill workers to analyze wage polarization. Section 7 considers an extension that allows for declining real prices of machines and one where workers endogenously choose between low-skill and high-skill employment. Section 8 concludes.

\section{The Model}

In this section, we introduce the model, and solve for wages and production in a given period. We consider a continuous time infinite-horizon economy populated by $H$ high-skill workers and $L$ low-skill workers. Both types of workers supply labor inelastically and have identical preferences over a single final good of:

$$
U_{k, t}=\int_{t}^{\infty} e^{-\rho(\tau-t)} \frac{C_{k, \tau}^{1-\theta}}{1-\theta} d \tau,
$$

where $\rho$ is the discount rate, $\theta \geq 1$ is the inverse elasticity of intertemporal substitution and $C_{k, t}$ is consumption of the final good at time $t$ by group $k \in\{H, L\}$.

The final good is produced by a competitive industry combining an endogenous set of intermediate inputs, $i \in \mathcal{N}_{t}=\left[0, N_{t}\right]$ using a CES aggregator:

$$
Y_{t}=\left(\int_{i \in \mathcal{N}_{t}} y_{t}(i)^{\frac{\sigma-1}{\sigma}} d i\right)^{\frac{\sigma}{\sigma-1}},
$$

where $\sigma>1$ is the elasticity of substitution between these inputs and $y_{t}(i)$ is the use of intermediate input $i$ at time $t$. We normalize the price of $Y_{t}$ to 1 at all points in time and drop time subscripts for the remainder of this section. The demand for each variety is:

$$
y(i)=p(i)^{-\sigma} Y
$$

where $p(i)$ is the price of intermediate input $i$ and the normalization implies that the ideal price index, $\left[\int_{i \in \mathcal{N}} p(i)^{1-\sigma} d i\right]^{1 /(1-\sigma)}$ equals 1 .

Each intermediate input is produced by a monopolist who owns the perpetual rights of production. She can produce the intermediate input by combining low-skill labor, $l(i)$, highskill labor, $h(i)$, and machines, $x(i)$, using the production function:

$$
y(i)=\left[l(i)^{\frac{\epsilon-1}{\epsilon}}+\alpha(i)(\tilde{\varphi} x(i))^{\frac{\epsilon-1}{\epsilon}}\right]^{\frac{\epsilon \beta}{\epsilon-1}} h(i)^{1-\beta},
$$

\footnotetext{
${ }^{6}$ In fact, figure 3 in Autor and Dorn (2013) shows that low-skill workers left non-service occupations from the 70's, which is consistent with the view that their tasks in non-service occupations were automated before the middle-skill workers' tasks.
} 
where $\alpha(i) \in\{0,1\}$ is an indicator function for whether or not the firm has access to an automation technology which allows for the use of machines (henceforth, we refer to such a firm and the product it produces as 'automated'). If the firm is not automated $(\alpha(i)=0)$, production takes place using a standard Cobb-Douglas production function with only low-skill and high-skill labor with a low-skill factor share of total costs of $\beta$. If the firm is automated $(\alpha(i)=1)$ it can substitute machines for low-skill workers with $\epsilon$ as the elasticity of substitution between the two (we allow for machines and low-skill workers to be perfect substitute in which case $\epsilon=\infty$ and the production function is $\left.y(i)=[l(i)+\alpha(i) \tilde{\varphi} x(i)]^{\beta} h(i)^{1-\beta}\right)$. High-skill workers always retain a factor share of $1-\beta$. The parameter $\tilde{\varphi}$ is the relative productivity advantage of machines over low-skill workers. Machines are an intermediate input in production and are wholly consumed in the production process. Throughout the paper we will refer to $x$ as 'machines', though our interpretation also includes any form of computer inputs, algorithms, the services of cloud-providers etc. Machines are produced competitively one for one with the final good and inherit a constant price of 1 . Though a natural starting point, this is an important assumption. We make it to show that when technical change is not directly laboraugmenting, several stylized facts — rising inequality and a falling labor share, in particular can be explained without relying on falling real cost of technology. However, with compelling evidence that the real cost of computing power has fallen dramatically (Nordhaus, 2007), we generalize our model to allow for an endogenously declining real price of machines in Section 7 .

Denoting low-skill wages $w$ and high-skill wages $v$, the unit cost of intermediate input $i$ is:

$$
c(w, v, \alpha(i))=\beta^{-\beta}(1-\beta)^{\beta-1}\left(w^{1-\epsilon}+\varphi \alpha(i)\right)^{\frac{\beta}{1-\epsilon}} v^{1-\beta},
$$

where $\varphi \equiv \tilde{\varphi}^{1 /(\epsilon-1)}, c(\cdot)$ is strictly increasing in both $w$ and $v$ and $c(w, v, 1)<c(w, v, 0)$ for all $w, v>0$. The monopolist charges a constant markup over costs such that price is $p(i)=\sigma /(\sigma-1) c(w, v, \alpha(i))$.

Using Shepard's lemma and equations (1) and (2) delivers the demand for low-skill labor of a single firm.

$$
l(w, v, \alpha(i))=\beta \frac{w^{-\epsilon}}{w^{1-\epsilon}+\varphi \alpha(i)}\left(\frac{\sigma-1}{\sigma}\right)^{\sigma} c(w, v, \alpha(i))^{1-\sigma} Y,
$$

which is decreasing in $w$ and $v$. The effect on demand for low-skill labor following automation is in general ambiguous. This is due to the combination of a negative substitution effect (the ability of the firm to substitute machines for low-skill workers) and a positive scale effect (the ability of the firm to employ machines decreases overall costs, lowers prices and increases production). The higher is $\mu \equiv \beta(\sigma-1) /(\epsilon-1)$ the higher is the relative importance of the scale effect. In this paper we focus on labor-substituting innovation and impose throughout that $\mu<1$ (equivalent to $\epsilon>1+\beta(\sigma-1)$ ) which is necessary and sufficient for the substitution effect to dominate and ensure $l(w, v, 1)<l(w, v, 0)$ for all $w, v>0$. It is straightforward to show that the relative use of skilled labor is increasing in automation as well, consistent with a large literature that finds technological improvements - in particular computerization — is associated with increased relative skill-use. ${ }^{7}$

\footnotetext{
${ }^{7}$ Autor, Katz, and Krueger (1998) and Machin and Van Reenen (1998) provide evidence on industry-level demand shifts. Doms, Dunne, and Troske (1997), Bartel, Ichniowski, and Shaw (2007) provide evidence at the firm level. Katz and Autor (1998) and Acemoglu and Autor (2011) provide summaries of the literature.
} 
Let $x(w, v)$ denote the use of a machines by an automated firm. The relative use of machines and low-skill labor for such a firm is then:

$$
\frac{x(w, v)}{l(w, v, 1)}=\varphi w^{\epsilon}
$$

demonstrating that the relative use of machines depends both on technological factors and economic factors; whether a firm is automated and the relative price of low-skill workers, respectively. As emphasized by Autor (2013) both are important for understanding the extent of automation and the role of the relative price of low-skill labor, $w$, will play an important role in this paper.

Factor market clearing implies that

$$
\int_{i \in \mathcal{N}} l(i) d i=L, \int_{i \in \mathcal{N}} h(i) d i=H
$$

where stocks of labor are kept constant. We relax this assumption in Section 7 where workers choose occupations based on relative wages and their heterogeneous skill-endowments.

Constant markups by intermediate input producers coupled with the unit elasticity of demand for high-skill labor ensure a constant factor share of high-skill labor of $v H=(1-\beta)(\sigma-$ $1) / \sigma Y$. Using this along with equations (1) and (2) gives profits of:

$$
\pi(w, v, \alpha(i))=\left(w^{1-\epsilon}+\varphi \alpha(i)\right)^{\mu} \frac{\beta^{(\sigma-1) \beta}(\sigma-1)^{(\sigma-1) \beta}}{\sigma^{(\sigma-1) \beta+1}} Y^{1-\psi^{-1}},
$$

where $\psi \equiv(\sigma-1)^{-1}(1-\beta)^{-1}$. The constant markup charged by the intermediate input producers allows us to write revenue as $r(w, v, \alpha(i))=\sigma \pi(w, v, \alpha(i))$. Hence, we can write the relative revenues of a non-automated firm compared with an automated firm as $r(w, v, 0) / r(w, v, 1)=$ $\left(1+\varphi w^{\epsilon-1}\right)^{-\mu}$, and note that it is a decreasing function of $w$; since non-automated firms rely more heavily on low-skill labor their relative market share drops with higher low-skill wages.

Let $\nu_{l}(w, v, \alpha(i))$ denote the share of revenues accruing to low-skill labor for intermediate input producer $i$ and analogously for high-skill workers, $h$, and machines, $x$. Using factor demand functions we have:

$$
\begin{gathered}
\nu_{l}(w, v, \alpha(i))=\frac{\sigma-1}{\sigma} \beta\left(1+\varphi w^{\epsilon-1} \alpha(i)\right)^{-1}, \\
\nu_{h}(w, v, \alpha(i))=\frac{\sigma-1}{\sigma}(1-\beta),
\end{gathered}
$$

and the share to machines is defined residually by $\nu_{l}(\cdot)+\nu_{h}(\cdot)+\nu_{x}(\cdot)=(\sigma-1) / \sigma$, with the remaining share $1 / \sigma$ accruing to the monopolist as profits. In an automated firm the relative factor payment of low- versus high-skill workers is fixed at $\beta /(1-\beta)$, whereas in automated firms, the ability to substitute for machines gives a relative share of $\left(1+\varphi w^{\epsilon-1}\right)^{-1} \beta /(1-\beta)$, which is decreasing in $w$.

Aggregate relative factor rewards must be a weighted average of the relative factor rewards in the two types of firms. Letting $G$ denote the fraction of intermediate input producers that are automated, we can sum over all intermediate input producers to get aggregate wages for lowskill workers as $w L=N\left[G r(w, v, 1) \nu_{l}(w, v, 1)+(1-G) r(w, v, 0) \nu_{l}(w, v, 0)\right]$, with an analogous expression for high-skill workers. This leads directly to an expression for the high-skill wage premium. 
Lemma 1. For $\epsilon<\infty$, the high-skill wage premium is given by

$$
\frac{v}{w}=\frac{(1-\beta)}{\beta} \frac{L}{H} \frac{G+(1-G)\left(1+\varphi w^{\epsilon-1}\right)^{-\mu}}{G\left(1+\varphi w^{\epsilon-1}\right)^{-1}+(1-G)\left(1+\varphi w^{\epsilon-1}\right)^{-\mu}},
$$

where $\partial v / \partial w>(1-\beta) L /(\beta H)$ for $G>0 .{ }^{8}$

For given $L / H$ the skill premium is (weakly) increasing in the absolute level of low-skill wages. This is so both because higher wages improve automated firms cost-advantage and thereby their market share (as reflected by the term $\left(1+\varphi \alpha(i) w^{\epsilon-1}\right)^{-\mu}$ in equation 7 ) and because automated firms substitute machines for low-skill workers (the term $\left.\left(1+\varphi w^{\epsilon-1}\right)^{-1}\right)$. Only in the special case of no automated firms, $G=0$, will the aggregate factor shares inherit that of a non-automated firm and $v / w=(1-\beta) L /(\beta H)$.

The skill-premium of equation $(7)$ is plotted in $(w, v)$ space in figure 1a below. For $G=0$ this is a straight line with slope $(1-\beta) L /(\beta H)$ shown as the dotted line. For any $G>0$ the use of machines shifts the curve to the left of the dotted line. Using that the combined factor share of low-skill workers and machines is constant gives $\left(\nu_{l}+\nu_{x}\right) / \nu_{h}=\beta /(1-\beta)$ for each firm. Aggregating for all firms then gives $w L+X=v H \beta /(1-\beta)$ such that the horizontal distance from the skill-premium curve to the dotted line gives the aggregate use of machines per low-skill worker $(X / L)$. Hence $X / L$ is low when $w$ is low as there is little incentive to rely on machines. As long as the economy cannot perfectly substitute machines for labor (that is as long as $\epsilon<\infty$ or $G<1$ ) the skill-premium curve will have a finite slope. Further, it is independent of $N$, but shifts to the left for increases in the share of automated firms, $G$.

We use demand for high-skill labor $h(w, v, \alpha(i))$ and the labor market clearing conditions to get:

$$
Y=\left(\frac{\sigma-1}{\sigma} \beta\right)^{\frac{\beta}{1-\beta}} H\left(G\left(\varphi+w^{1-\epsilon}\right)^{\mu}+(1-G) w^{\beta(1-\sigma)}\right)^{\psi} N^{\psi} .
$$

Again we use that $v H=(1-\beta)(\sigma-1) Y / \sigma$ to plot equation 8 in Figure 1a as well. We label it as the productivity condition as it gives the highest $Y$ (and thereby $v$ ) that a given $N, G, w$ can deliver. Improvements in either type of technology, $G$ or $N$, will shift the productivity condition to the northeast. We can combine these two to get the absolute pay for low-skill workers as the intersection of the skill-premium and productivity conditions.

Proposition 1. For $\epsilon<\infty$, the absolute pay for low-skill workers $w$ is uniquely determined by:

$$
w=\frac{\sigma-1}{\sigma} \beta\left(\frac{H}{L}\right)^{1-\beta} N^{\frac{1}{\sigma-1}} \frac{\left(G\left(1+\varphi w^{\epsilon-1}\right)^{\mu-1}+(1-G)\right)^{1-\beta}}{\left(G\left(1+\varphi w^{\epsilon-1}\right)^{\mu}+(1-G)\right)^{\frac{\psi^{-1}-1}{\sigma-1}}} .
$$

$w$ is an increasing function in $N$.

(i) When $\beta /(1-\beta)>\epsilon-1$ : $w$ is either increasing in $G$ (for a low $N$ ) or 'inverse $u$ '-shaped in $G$ (for a large $N$ ) with $\left.w\right|_{G=0}<\left.w\right|_{G=1}$.

(ii) When $\beta /(1-\beta)=\epsilon-1$ : $w$ is 'inverse $u$ '-shaped in $G$ with $\left.w\right|_{G=0}=\left.w\right|_{G=1}$.

\footnotetext{
${ }^{8}$ When machines and low-skill workers are perfect substitutes, $\epsilon=\infty$, the skill premium is given by $\frac{v}{w}=$ $\frac{(1-\beta)}{\beta} \frac{L}{H}$ if $w<\widetilde{\varphi}^{-1}$ such that no firm uses machines, and $\frac{v}{w}=\frac{(1-\beta)}{\beta} \frac{L}{H} \frac{G+(1-G)(\widetilde{\varphi} w)^{-1}}{(1-G)(\widetilde{\varphi} w)^{-1}}$ if $w>\widetilde{\varphi}^{-1}$.
} 
(iii) When $\beta /(1-\beta)<\epsilon-1$ : $w$ is either decreasing in $G$ (for a low $N$ ) or 'inverse $u$ '-shaped in $G$ (for a large $N$ ) with $\left.w\right|_{G=0}>\left.w\right|_{G=1} \cdot{ }^{9}$

The impact of an increase in $N$ is unambiguously positive for both $w$ and $v$. As the skillpremium condition is upward sloping and invariant to changes in $N$, any increase in $N$ pushes out the productivity condition and raises low-skill wages. Higher low-skill wages will encourage substitution away from low-skill workers to machines and increase $X / L$ but insufficiently to counter the raise in $w$.

The impact of an increase in the share of automated firms $G$ on the real wage $w$ can be understood through the interaction of an aggregate substitution effect - the leftward movement of the skill-premium condition - and an aggregate productivity effect - the outward shift in the productivity condition. Automated firms hire less labor (everything else constant), but automation leads to a productivity gain for the economy as a whole. The relative strength of the aggregate productivity effect depends on whether $\beta /((1-\beta)(\epsilon-1))$ is smaller, equal to, or greater than 1. A larger factor share $\beta$ for machines/low-skill workers makes the aggregate scale effect stronger, whereas a larger elasticity of substitution, $\epsilon$, makes the aggregate substitution effect stronger. Hence, a complete transition from all firms being non-automated to all firms being automated will benefit low-skill workers if and only if $\beta /(1-\beta)>\epsilon-1$.

The effects for marginal increases in the automation fraction, $G$, are more subtle. However, for sufficiently high $N$ - and consequently sufficiently high $w-w$ is always 'inverse u'-shaped in $G$. When $w$ is high and savings from automation are consequently high, a low $G$ tends to favor the aggregate scale effect over the aggregate substitution effect. Hence, automating the first intermediary input leads to a large gain in production as the automated firm can capture a large market share and improve overall productivity, while automating the last intermediary input represents a sharp reduction in low-skill labor demand since no firms will now rely only on low-skill and high-skill labor. ${ }^{10}$

\section{Asymptotic Growth Rates for General Technological Processes}

We now derive the implications of Lemma 1 and Proposition 1 for general (continuous) processes of the mass of products $N_{t}$ and the fraction that is automated, $G_{t}$ (in section 4 below, we choose a particular specification to endogenize the evolution of $N_{t}$ and $G_{t}$ ). For any variable $a_{t}$, let $g_{t}^{a}=\dot{a}_{t} / a_{t}$ denote its growth rate, $g_{\infty}^{a}=\lim _{t \rightarrow \infty} g_{t}^{a}$ the asymptotic growth rate, and $a_{\infty}=\lim _{t \rightarrow \infty} a_{t}$ the asymptotic limit if such exists. The following proposition considers the asymptotic growth rate of $w_{t}$.

Proposition 2. Consider two processes $\left[N_{t}\right]_{t=0}^{\infty}$ and $\left[G_{t}\right]_{t=0}^{\infty}$ where $\left(N_{t}, G_{t}\right) \in(0, \infty) \times[0,1]$ for

\footnotetext{
${ }^{9}$ When machines and low-skill workers are perfect substitutes $\epsilon=\infty, w$ is given by $w=\frac{\sigma-1}{\sigma} \beta\left(\frac{H}{L}\right)^{1-\beta} N$ if $w<\widetilde{\varphi}^{-1}$ and $w=\frac{\sigma-1}{\sigma} \beta\left(\frac{H}{L}\right)^{1-\beta} N^{\frac{1}{\sigma-1}}(1-G)^{1-\beta}\left(G(\widetilde{\varphi} w)^{\beta(\sigma-1)}+1-G\right)^{\frac{1-(1-\beta)(\sigma-1)}{\sigma-1}}$ if $w>\widetilde{\varphi}^{-1}$; otherwise, $w=\widetilde{\varphi}^{-1}$ and the latter expression still holds but replacing $G$ the share of firms who have the automation technology with $G_{\text {eff }} \leq G$ the share of firms who use the automation technology. $w$ is (weakly) increasing in $N$, and either (weakly) decreasing in $G$ (for a low $N$ ) or (weakly) 'inverse u'-shaped in $G$ (for a larger $N$ ).

${ }^{10}$ Formally, we get the semi-elasticity of $w$ with respect to $G$ by taking the log of (9) and differentiating. We can then write that $\frac{\partial \ln (w)}{\partial G}$ as proportional to the sum of two terms: $\frac{\partial \ln (w / v)}{\partial G}$, given by (7), which is negative and represents the substitution effect, and $\frac{\partial \ln Y}{\partial G}$ which is positive and represents the productivity effect. The ratio of the absolute value of the substitution effect over the productivity effect is increasing in $G$.
} 


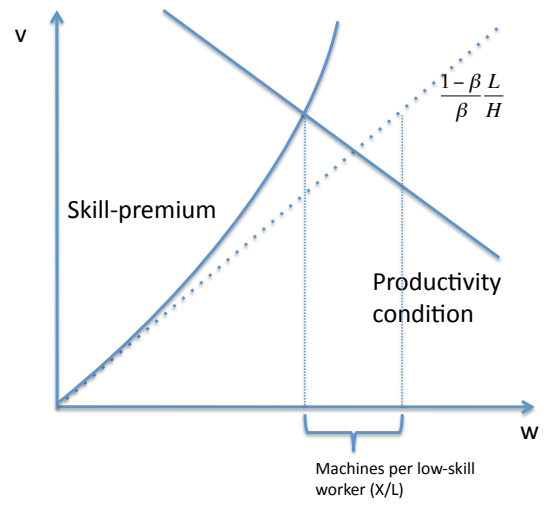

(a) The Equilibrium Wages

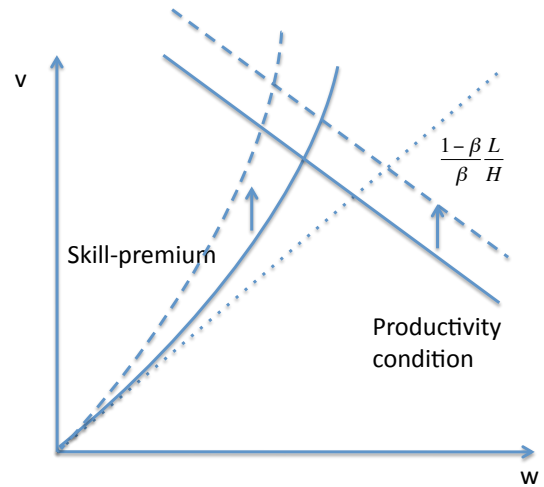

(b) An Increase in Share of Automated Products: An increase in $G$ enables higher substitution towards machines and shifts the Skill-premium to the left. An increase in $G$ pushes the Productivity Condition outwards. High-skill wages must increase, but low-skill wages can potentially decrease.

Figure 1: The Equilibrium Wage Premium: The skill-premium condition is upward sloping and steeper than the dotted line: for given $G$ if low-skill wages increase, automated firms will capture larger market share and substitute machines for low-skill workers increasing the skill-premium $(v / w)$. The skill-premium is independent of $N$, whereas a higher $G$ pivots the skill-premium counter-clockwise. The Productivity condition is downward sloping and is pushed outward by increases in $N$ or $G$. 
all $t$. If a limit exists for $G_{t}$ and there is asymptotic positive growth in $N_{t}$, (i.e. there exists some $\bar{t}$ and $\underline{g}^{N}>0$ for which $g_{t}^{N} \geq \underline{g}^{N}$ for all $t>\bar{t}$ ) then:

Part A) If $0<\lim _{t \rightarrow \infty} G_{t}<1$ then

- The asymptotic growth rate of $w_{t}$ is positive at

$$
g_{\infty}^{w}=\frac{1}{(1+\beta(\sigma-1))} g_{\infty}^{Y}
$$

Part B). If $\lim _{t \rightarrow \infty} G_{t}=1$ and $G_{t}$ converges sufficiently fast (more specifically if

$\lim _{t \rightarrow \infty}\left(1-G_{t}\right) N_{t}^{\psi(1-\mu) \frac{\epsilon-1}{\epsilon}}$ exists and is finite) then

- If $\epsilon<\infty$ the asymptotic growth rate of $w_{t}$ is positive at:

$$
g_{\infty}^{w}=\frac{1}{\epsilon} g_{\infty}^{Y}
$$

where $[1+\beta(\sigma-1)]^{-1}>\epsilon^{-1}$ by the assumption that $\mu<1 .^{11}$

- If low-skill workers and machines are perfect substitutes then lim $_{t \rightarrow \infty} w_{t}$ is finite and weakly greater than $\tilde{\varphi}^{-1}$ (equal to $\tilde{\varphi}^{-1}$ when $\lim _{t \rightarrow \infty}\left(1-G_{t}\right) N_{t}^{\psi}=0$ )

Proof. First, we note from Proposition 1 that $w$ is increasing in $N_{t}$. For Part A) replace $G_{t}$ with its limit (less than 1) and let $N_{t} \rightarrow \infty$. Using equation 9 gives the result. For Part B) when $\lim _{t \rightarrow \infty}\left(1-G_{t}\right) N_{t}^{\psi(1-\mu) \frac{\epsilon-1}{\epsilon}}=0$, and $\epsilon<\infty$, we can replace $G_{t}$ with the limit of 1 and the growth rate follows. For the case of perfect substitutes (with $\lim _{t \rightarrow \infty}\left(1-G_{t}\right) N_{t}^{\psi}=0$ ) the result follows by contradiction. See appendix for further details.

The proposition states that in the case of asymptotically positive growth in $N_{t}$ mild assumptions are sufficient to guarantee an asymptotic positive growth rate of $w_{t}$. To see why, consider first the case in which $\lim _{t \rightarrow \infty} G_{t}<1$. If low-skill wages were to remain constant, the relative demand for low-skill workers versus machines would remain constant as well. As the economy grows so does the demand for the non-automated products and therefore for low-skill labor. With a fixed supply of low-skill labor, labor markets would not clear. Hence, low-skill wages must increase. As low-skill wages increase so does the relative market share of automated firms and their reliance on machines, both of which ensure that low-skill wages grow at a lower rate than the economy. How much lower depends on $\sigma$ and $\beta$ : for growing low-skill wages a higher importance of low-skill workers (a higher $\beta$ ) or a higher substitutability between automated and non-automated products (a higher $\sigma$ ) implies a faster loss of competitiveness of the non-automated firms and a lower growth rate of low-skill wages. The growth rate of $w_{t}$ is independent of the elasticity of substitution between machines and low-skill workers, $\epsilon$, as the income received by low-skill workers from automated firms becomes negligible relative to the income earned from non-automated firms.

Now, consider the case of $\lim _{t \rightarrow \infty} G_{t}=1$ such that asymptotically all products are automated and the convergence happens fast enough (relative to the growth in $N_{t}$ ) to satisfy the condition in Part B of Proposition 2. If there is less than perfect substitutability between workers and machines within automated firms $(\epsilon<\infty)$, then an analogous argument-by-contradiction shows that low-skill wages must increase asymptotically, though the growth rate relative to

\footnotetext{
${ }^{11}$ If $\lim _{t \rightarrow \infty}\left(1-G_{t}\right) N_{t}^{\psi(1-\mu) \frac{\epsilon-1}{\epsilon}}=\infty$ then $\frac{1}{\epsilon} g_{\infty}^{Y} \leq g_{\infty}^{w} \leq \frac{1}{1+\beta(\sigma-1)} g_{\infty}^{Y}$
} 
that of the economy must now be lower as the automated firms more readily substitute workers for machines than the economy substitutes from non-automated to automated products. The relative growth of low-skill wages now depends on $\epsilon$ as the fraction of non-automated firms becomes zero.

Only in the special case in which machines and low-skill workers are perfect substitutes in the production by automated firms and the share of automated firms is asymptotically 1 will there be economy-wide perfect elasticity between low-skill workers and machines. ${ }^{12}$ In this case, $w_{t}$ cannot grow asymptotically, but will still be bounded below by $w_{t} \geq \tilde{\varphi}^{-1}$, since a lower wage would imply that no firm would use machines.

It is important to recognize that the proof of Proposition 2 relies on the same production technology making both machines and the consumption good. To see this, let $p_{t}^{C}$ and $p_{t}^{x}$ denote the price levels of the consumption good and machines, respectively. Hence, we can write the real wage of low-skill workers as the product of the relative cost of workers relative to machines and the real price of machines: $w_{t} / p_{t}^{C}=\left(w_{t} / p_{t}^{x}\right)\left(p_{t}^{x} / p_{t}^{C}\right)$. As argued above any finite economy-wide elasticity of substitution between low-skill workers and machines must result in asymptotically increasing relative price of low-skill workers, $w_{t} / p_{t}^{x}$. As $p_{t}^{x} / p_{t}^{C}$ is constant by assumption the real wage must increase as a consequence. A generalized version of Proposition 2 in section 7 allows for asymptotic (negative) growth in $p_{t}^{x} / p_{t}^{C}$ and thereby potentially decreasing real wage for low-skill workers.

In general the processes of $N_{t}$ and $G_{t}$ will depend on the rate at which new products are introduced, the extent to which they are initially automated, and the rate at which non-automated firms are automated. Autor (2013) argues that the technological process of automation is best understood as a uni-directional shift. When a task is new and unfamiliar, the flexibility and outside experiences of workers allow them to solve unforeseen problems. As the task becomes routine and potentially codefiable a machine (or an algorithm) can perform it. The replaced workers must then move on to new tasks, not yet automated. The following lemma formalized this idea in the context of the present model.

Lemma 2. Consider a process of $\left[N_{t}\right]_{t=0}^{\infty}$ with asymptotic positive growth. Then if $i$ ) the probability that a new product starts out non-automated is bounded below away from zero and ii) the intensity at which non-automated firms are automated is bounded above and below away from zero, then any limit of $G_{t}$ must have $0<\lim _{t \rightarrow \infty} G_{t}<1$.

Proof. Note that $G_{t} N_{t}$ is the mass of automated firms and let $\nu_{1, t}>0$ be the intensity at which non-automated firms are automated at time $t$ and $0 \leq \nu_{2, t}<1$ be the fraction of new products introduced at time $t$ that are initially automated. Then $\left(G_{t} N_{t}\right)=\nu_{1, t}\left(1-G_{t}\right) N_{t}+\nu_{2, t} \dot{N}_{t}$ such that $\dot{G}_{t}=\nu_{1, t}\left(1-G_{t}\right)-\left(G_{t}-\nu_{2, t}\right) g_{t}^{N}$. First assume that $\lim _{t \rightarrow \infty} G_{t}=1$, then if $\nu_{1, t}<\bar{\nu}_{1}<\infty$ and $\nu_{2, t}<\bar{\nu}_{2}<1$, we get that $\dot{G}_{t}$ must be negative for sufficiently large $t$, which contradicts the assumption that $\lim _{t \rightarrow \infty} G_{t}=1$. Similarly if $\lim _{t \rightarrow \infty} G_{t}=0$, then having $\nu_{1, t}>\underline{\nu}$ for all $t$,

\footnotetext{
${ }^{12}$ There is no universal agreement on the proper extension of the elasticity of substitution when production, as here, uses more than 2 factors. Blackorby and Russell (1981) discuss the differences between 3 often used definitions. The present model, however, is invariant to which one of these extensions is used. One can show that the economy admits an aggregate cost function $C\left(w, v, p^{x}, Y\right)$, where $p^{x}$ and $Y$ are the price of machines and total production of the final good, respectively. The cost function inherits all the properties of a standard cost function and delivers a relative use of machines and labor of $X / L=\varphi\left(w / p^{x}\right)^{\epsilon} G\left(G+\left(1+\varphi\left(w / p^{x}\right)^{\epsilon-1}\right)^{1-\mu}(1-G)\right)^{-1}$. It is easy to verify that the elasticity of substitution, $d \ln (X / L) / d \ln \left(w / p^{x}\right)$, is finite for either $\epsilon<\infty$ or $G<1$.
} 
gives that $\dot{G}_{t}$ must be positive for sufficiently large $t$, which also implies a contradiction. Hence a limit must have $0<\lim _{t \rightarrow \infty} G_{t}<1$.

The conditions of Lemma 2 represents a continuous shift of low-skill workers from recently automated to still non-automated firms. As long as new products enter with production techniques that are (at least not all) sufficiently routine so as to be automated, at any point in time a positive fraction will remain non-automated and $\lim _{t \rightarrow \infty} G_{t}<1$. It is only in the special case of all new products starting out automated (or asymptotically equivalently the intensity with which they are automated increases without bounds) that it is possible for $\lim _{t \rightarrow \infty} G_{t}=1$. In all other cases, Part A of Proposition 2 will govern the asymptotic properties of $g_{t}^{w}$.

It is worth noting that alternative conditions are sufficient to guarantee $0<\lim _{t \rightarrow \infty} G_{t}<1$. In particular, amending the conditions of Proposition 2 to allow for some products to be automated with positive probability and others not at all would also imply $0<\lim _{t \rightarrow \infty} G_{t}<1$. Hence, the results of Proposition 2 do not depend on all products being potentially automatable. $^{13}$

\section{A Dynamic Model}

To study the determinants of automation and horizontal innovation, we now endogenize the processes of $N_{t}$ and $G_{t}$ as the consequence of intentional innovation, though we keep in mind that the results of Proposition 2 and Lemma 2 will hold in more general settings.

\subsection{Innovation Technologies}

We first introduce the innovation technology for automation. Let $V_{t}^{A}$ denote the value of an automated firm and $r_{t}$ the economy wide interest rate. The asset pricing equation for such a firm is given by

$$
r_{t} V_{t}^{A}=\pi_{t}^{A}+\dot{V}_{t}^{A}
$$

where we ease notation by defining $\pi_{t}^{A} \equiv \pi\left(w_{t}, v_{t}, 1\right)$ as profits at time $t$ by an automated firm. The equation states that the required return on holding an automated firm, $V_{t}^{A}$, must equal the instantaneous profits plus appreciation. An automated firm only maximizes instantaneous profits and has no intertemporal investment decisions to make. A non-automated firm, on the other hand, has to decide how much to invest in becoming automated.

Denote the value of a non-automated firm $V_{t}^{N}$. Such a firm can invest $z_{t}^{A}$ every period to automate with the Poisson process of $\eta\left(z_{t}^{A} G_{t}^{\chi} N_{t}^{1-\psi}\right)^{\kappa}$, where $\eta>0,0<\kappa<1$ and $0 \leq$ $\chi \leq 1$. Rewriting the technological levels as $\left(G_{t} N_{t}\right)^{\chi} N_{t}^{1-\psi-\chi}$ makes clear that the efficiency of automation depends on the level of technology, $N_{t}$, as well as (weakly) positively on the stock of varieties that are already automated, $G_{t} N_{t}$. The normalization with respect to $N_{t}^{1-\psi}$ ensures that an asymptotic steady state can exist. With this in hand, the asset pricing equation for a non-automated firm is:

$$
r_{t} V_{t}^{N}=\left(1+\varphi w_{t}^{\epsilon-1}\right)^{-\mu} \pi_{t}^{A}+\eta\left(z_{t}^{A} G_{t}^{\chi} N_{t}^{1-\psi}\right)^{\kappa}\left(V_{t}^{A}-V_{t}^{N}\right)-z_{t}^{A}+\dot{V}_{t}^{N}
$$

\footnotetext{
${ }^{13}$ In spite of this, in the following we still allow all products to be automatable. This is partly done for tractability and partly because it does not seem like a restrictive assumption in the long-run. Autor, Levy, and Murnane (2003) give the example of navigating a car through traffic as a set of skills beyond computers, yet 10 years later Google's driverless car seems to be doing just that.
} 
which has an analogous interpretation to equation (12), except instantaneous profits are lower $\left(\left(1+w_{t}^{\epsilon-1}\right)^{-\mu}<1\right)$ and profits are augmented by the instantaneous expected gain from innovation $\eta\left(z_{t}^{A} G_{t}^{\chi} N_{t}^{1-\psi}\right)^{\kappa}\left(V_{t}^{A}-V_{t}^{N}\right)$ net of expenditure on automation research, $z_{t}^{A}$. The first order condition for automation innovation follows as:

$$
G_{t}^{\chi} N_{t}^{1-\psi} \eta \kappa\left(z_{t}^{A} G_{t}^{\chi} N_{t}^{1-\psi}\right)^{\kappa-1}\left(V_{t}^{A}-V_{t}^{N}\right)=1
$$

which must hold at all points in time for all non-automated firms. Therefore R\&D expenditures in automation increase with the difference in value between automated and non-automated firms, and everything else constant an increase in low-skill workers' wages increases R\&D expenditures in automation. ${ }^{14}$ This returns total expenditure on automation research of:

$$
Z_{t}^{A}=\left(1-G_{t}\right) N_{t} z_{t}^{A} .
$$

We specify innovation in new products in a standard manner. There is a fringe of outside entrepreneurs who employ a linear technology which, by the use of $Z_{t}^{D}$ of the final good, increases the stock of new products by:

$$
\dot{N}_{t}=\gamma N_{t}^{1-\psi} Z_{t}^{D}
$$

where $\gamma>0$ is a measure of the overall productivity of the horizontal innovation technology. We refer to $Z_{t}^{D}$ as horizontal R\&D expenditures. All new products are initially non-automated. ${ }^{15}$ The value of a new product is $V_{t}^{N}$ and free entry by entrepreneurs requires that:

$$
\gamma V_{t}^{N} N_{t}^{1-\psi} \leq 1
$$

which must hold at all times and with equality if there is strictly positive innovation $\left(\dot{N}_{t}>0\right)$.

\subsection{Equilibrium Definition and Characterization}

Market clearing for the final good requires

$$
Y_{t}=C_{t}+X_{t}+Z_{t}^{D}+Z_{t}^{A}
$$

where $C_{t}=C_{L, t}+C_{H, t}$ is total consumption at time $t$ and $X_{t}=G_{t} N_{t} x_{t}\left(w_{t}, v_{t}\right)$ is total use of machines.

Finally, the low-skill and high-skill representative household's problems are standard and lead to Euler equations which in combination give

$$
\frac{\dot{C}_{t}}{C_{t}}=\frac{1}{\theta}\left(r_{t}-\rho\right)
$$

with a transversality condition requiring that the present value of all assets in the economy the aggregate value of the intermediate input producers - is asymptotically zero.

$$
\lim _{t \rightarrow \infty}\left(\exp \left(-\int_{0}^{t} r_{s} d s\right) N_{t}\left(\left(1-G_{t}\right) V_{t}^{N}+G_{t} V_{t}^{A}\right)\right)=0
$$

We can then define a feasible allocation and an equilibrium as follows:

\footnotetext{
${ }^{14}$ This claim is obtained for constant $v, Y, \dot{V}_{t}^{N}, \dot{V}_{t}^{A}, r_{t}$ using (6), (12), (13) and (14).

${ }^{15}$ Recall that the combination of Proposition 2 and Lemma 2 implies that the asymptotic growth rate of $w_{t}$ is independent of the initial fraction of new products that are non-automated as long as this fraction is asymptotically positive. Naturally, the level of pay will depend on this assumption.
} 
Definition 1. A feasible allocation is defined by time paths of stock of varieties and share of those that are automated, $\left[N_{t}, G_{t}\right]_{t=0}^{\infty}$, time paths of use of low-skill labor, high-skill labor, and machines in the production of intermediary inputs and expenditures on automation R\&D, $\left[l_{t}(i), h_{t}(i), x_{t}(i), z_{t}^{A}(i)\right]_{i \in \mathcal{N}_{t}, t=0}^{\infty}$, time path of intermediary inputs production $\left[y_{t}(i)\right]_{i \in \mathcal{N}_{t}, t=0}^{\infty}$, time paths of final good production levels, consumption levels, and horizontal R\&D expenditures $\left[Y_{t}, C_{t}, Z_{t}^{D}\right]_{t=0}^{\infty}$ such that factor markets clear ((5) holds) and good market clears ((15) holds).

Definition 2. An equilibrium is a feasible allocation, a time path of intermediary input prices $\left[p_{t}(i)\right]_{i \in \mathcal{N}_{t}, t=0}^{\infty}$, a time path for low-skill wages, high-skill wages, interest rate and the value of non-automated and automated firms $\left[w_{t}, v_{t}, r_{t}, V_{t}^{N}, V_{t}^{A}\right]_{t=0}^{\infty}$ such that $\left[y_{t}(i)\right]_{i \in \mathcal{N}_{t}, t=0}^{\infty}$ maximizes final good producer profits, $\left[p_{t}(i), l_{t}(i), h_{t}(i), x_{t}(i)\right]_{i \in \mathcal{N}_{t}, t=0}^{\infty}$ maximize intermediary inputs producers' profits, $\left[z_{t}^{A}(i)\right]_{i \in \mathcal{N}_{t}, t=0}^{\infty}$ maximizes the value of non-automated firms, $\left[Z_{t}^{D}\right]_{t=0}^{\infty}$ is determined by free entry, $\left[C_{t}\right]_{t=0}^{\infty}$ is consistent with consumer optimization and the transversality condition is satisfied.

In order to work with an asymptotic stable system we normalize variables by defining normalized expenditures on automation as $\hat{z}_{t}^{A} \equiv z_{t}^{A} N_{t}^{1-\psi}$, normalized profits for an automated firm as $\hat{\pi}_{t}^{A}=\pi_{t}^{A} N_{t}^{1-\psi}$, and normalized aggregate consumption $\hat{C}_{t} \equiv C_{t} N_{t}^{-\psi}$. Further, we define $n_{t} \equiv N_{t}^{-\beta /[(1-\beta)(1+\beta(\sigma-1))]}$ and $\omega_{t} \equiv w_{t}^{\beta(1-\sigma)}$. This allows us to write the system as one of four differential equations for $\left(n_{t}, G_{t}, \hat{z}_{t}^{A}, \hat{C}_{t}\right)$ with 3 auxiliary variables $\left(\hat{\pi}_{t}, \omega_{t}, g_{t}^{N}\right)$. The four differential equations are as follows:

$$
\begin{gathered}
\dot{n}_{t}=-\frac{\beta}{(1-\beta)(1+\beta(\sigma-1))} g_{t}^{N} n_{t} \\
\dot{G}_{t}=\eta\left(G_{t}^{\chi} \hat{z}_{t}^{A}\right)^{\kappa}\left(1-G_{t}\right)-G_{t} g_{t}^{N} \\
\dot{\hat{z}}_{t}^{A}=\gamma \frac{\eta \kappa}{1-\kappa}\left(G_{t}^{\chi} \hat{z}_{t}^{A}\right)^{\kappa}\left(\left(1+\varphi \omega_{t}^{-1 / \mu}\right)^{-\mu} \hat{\pi}_{t}+\frac{1-\kappa}{\kappa} \hat{z}_{t}^{A}\right)\left(\frac{1}{\gamma}+\frac{\hat{z}_{t}^{A}\left(G_{t}^{\chi} \hat{z}_{t}^{A}\right)^{1-\kappa}}{\eta \kappa}\right)-\frac{\eta \kappa}{1-\kappa}\left(G_{t}^{\chi} \hat{z}_{t}^{A}\right)^{\kappa} \hat{\pi}_{t} \\
+\frac{\kappa \chi}{(1-\kappa)} \hat{z}_{t}^{A}\left(\eta\left(G_{t}^{\chi} \hat{z}_{t}^{A}\right)^{\kappa}\left(1-G_{t}\right) / G_{t}-g_{t}^{N}\right) \\
\dot{\hat{C}}_{t}=\frac{\hat{C}_{t}}{\theta}\left[\gamma\left(1+\varphi \omega_{t}^{-1 / \mu}\right)^{-\mu} \hat{\pi}_{t}+\gamma \frac{1-\kappa}{\kappa} \hat{z}_{t}^{A}-\rho-\left(\theta+\psi^{-1}-1\right) \psi g_{t}^{N}\right]
\end{gathered}
$$

and the auxiliary conditions are

$$
\begin{gathered}
\hat{\pi}_{t}=\left(\frac{\beta^{\beta}(\sigma-1)^{\beta}}{\sigma}\right)^{\frac{1}{1-\beta}}\left(\omega_{t}^{1 / \mu}+\varphi\right)^{\mu} H\left(G_{t}\left(\omega_{t}^{1 / \mu}+\varphi\right)^{\mu}+\left(1-G_{t}\right) \omega_{t}\right)^{\psi-1}, \\
\omega_{t}=n_{t}\left[\left(\frac{\sigma-1}{\sigma} \beta\right)^{\frac{-\beta(\sigma-1)}{1-\beta}}\left[\begin{array}{c}
\left(\frac{H}{L}\left(G_{t}\left(1+\varphi \omega_{t}^{-1 / \mu}\right)^{\mu-1}+\left(1-G_{t}\right)\right)\right)^{-\beta(\sigma-1)} \times \\
\left(G_{t}\left(\omega_{t}^{1 / \mu}+\varphi\right)^{\mu}+\left(1-G_{t}\right) \omega_{t}\right)^{-\frac{\beta(1-(1-\beta)(\sigma-1))}{1-\beta}}
\end{array}\right]\right]^{\frac{1}{1+\beta(\sigma-1)}},
\end{gathered}
$$




$$
g_{t}^{N}=\gamma\left\{\left[\begin{array}{c}
\left(\left(1-\beta \frac{\frac{\sigma-1}{\sigma} \varphi}{\omega_{t}^{1 / \mu}+\varphi}\right) G_{t}\left(\omega_{t}^{1 / \mu}+\varphi\right)^{\mu}+\left(1-G_{t}\right) \omega_{t}\right) \times \\
\left(\frac{\sigma-1}{\sigma} \beta\right)^{\frac{\beta}{1-\beta}} H\left(G_{t}\left(\omega_{t}^{1 / \mu}+\varphi\right)^{\mu}+\left(1-G_{t}\right) \omega_{t}\right)^{\psi-1}
\end{array}\right]-\left(1-G_{t}\right) \hat{z}_{t}^{A}-\hat{C}_{t}\right\} .
$$

Equation (16) follows directly from the definition of $n_{t}$. Equation (17) shows the evolution of the fraction of varieties that are automated. The first term corresponds to existing products being automated, whereas the second term reflects the introduction of new varieties which are initially not automated. Equation (18) governs the transition of normalized automated expenditures $\hat{z}_{t}^{A}$ and follows from a no-arbitrage condition of equality between the returns on a non-automated firm and that of an automated firm. ${ }^{16}$ Equation (19) follows from rewriting the Euler equation and using the return on a non-automated firm (equation 13) to substitute for the interest rate.

The auxiliary equations (20) and (21) are the normalized forms of equations (6) and (9), whereas equation (22) follows from noting that the horizontal innovation technology requires $g_{t}^{N}=\dot{N}_{t} / N_{t}=\gamma N_{t}^{-\psi} Z_{t}^{D}$ and employing the market clearing condition for the final good. We add the following condition on parameters

\section{Assumption:}

Parameters are such that

$$
\rho\left(\frac{1}{\eta \kappa^{\kappa}(1-\kappa)^{1-\kappa}}\left(\frac{\rho}{\gamma}\right)^{1-\kappa}+\frac{1}{\gamma}\right)<\left(\frac{\beta^{\beta}(\sigma-1)^{\beta}}{\sigma}\right)^{\frac{1}{1-\beta}} \varphi^{\mu \psi} H .
$$

This assumption is a sufficient condition for the existence of a steady-state $\left(n^{*}, G^{*}, \hat{z}^{A *}, \hat{C}^{*}\right)$ for our normalized system of differential equations (16), (17), (18) and (19) with $n^{*}=0$, and positive growth $\left(g^{N}\right)^{*}>0$. We will refer to this steady-state as an asymptotic steady-state for our original system of differential equations. The assumption is satisfied by a sufficiently low $\rho$ or sufficiently high $H$. Moreover, $\eta>0$ is a necessary requirement for asymptotic positive growth rate. Without automation there is asymptotically insufficient incentive to introduce new products and growth stops asymptotically. This result is more general than this specific model. Since automation allows the economy to replace a limited input (labor) with machines produced from the continuously growing supply of the final good, it removes a scarcity constraint imposed on the economy by the fixed mass of low-skill workers. As low-skill wages grow the difference in profits between automated and non-automated firms grow correspondingly. Any horizontal innovation technology that would allow for a continuous incentive to innovate without automation, would have continuously increasing growth with automation precluding constant positive asymptotic growth.

\footnotetext{
${ }^{16}$ Specifically, the normalized returns are $\hat{V}_{t}^{N} \equiv V_{t}^{N} N_{t}^{1-\psi}$ and $\hat{V}_{t}^{A} \equiv V_{t}^{A} N_{t}^{1-\psi}$. Free entry ensures $\hat{V}_{t}^{N}=1 / \gamma$ for all $t$, such that we can write equations (12) and (13) as: $\left[\left(1+w_{t}^{\epsilon-1}\right)^{-\mu} \hat{\pi}_{t}+(1-\kappa) / \kappa \hat{z}_{t}^{A}\right] / \gamma^{-1}=$ $\left[\hat{\pi}_{t}+(1-\kappa) /\left(\eta G_{t}^{\chi \kappa} \kappa\right)\left(\hat{z}^{A}\right)^{-\kappa} \dot{\hat{z}}_{t}^{A}\right] /\left(\left(\hat{z}_{t}^{A}\right)^{1-\kappa} /\left(\eta G_{t}^{\chi \kappa} \kappa\right)+1 / \gamma\right)$, where the numerator on the left hand side reflects the return on a non-automated firm (the flow of profits plus the expected gain from automation research), and the numerator on the right hand side reflects profit flows $\hat{\pi}_{t}$ plus appreciation $\dot{\hat{V}}_{t}^{A}$ for an automated firm, while the denominators are respectively the (normalized) value of a non-automated and an automated firm. The substitution with $\hat{z}_{t}^{A}$ follows from the one-to-one monotone positive relationship between (normalized) automation research and the value of an automated firm from the first order condition (14): $\eta G_{t}^{\chi \kappa} \kappa\left(\hat{z}_{t}^{A}\right)^{\kappa-1}\left(\hat{V}_{t}^{A}-1 / \gamma\right)=1$. Noting that the automation research function ensures strictly positive $\hat{z}_{t}^{A}$ allows us to rewrite the no-arbitrage equation as equation (18).
} 
The assumption that $\theta \geq 1$ ensures that the transversality condition always holds. ${ }^{17}$ With this in mind we can demonstrate the following proposition:

Proposition 3. Consider parameters for which the asymptotic steady-state is unique and saddle-path stable. ${ }^{18},{ }^{19}$ For an initial pair $\left(N_{t_{0}}, G_{t_{0}}\right) \in(0, \infty) \times[0,1]$ (with $G_{t_{0}}>0$ if $\chi>0$ ) sufficiently close to the asymptotic steady-state, the model features a unique equilibrium. It holds that high-skill wages, $v_{t}$, and $Y_{t}$ grow at the same rate:

$$
g_{t}^{v}=g_{t}^{Y} \text {, for all } t .
$$

Asymptotically, so does total spending on automation, $N_{t}\left(1-G_{t}\right) z_{t}^{A}$, total spending on innovation of new products $Z_{t}^{D}$ and consumption, $C_{t}$. This growth rate is proportional to the growth rate of $N$

$$
g_{\infty}^{Y}=\psi g_{\infty}^{N}
$$

Low-skill wages grow asymptotically as in Part A of Proposition 2:

$$
g_{\infty}^{w}=\frac{1}{(1+\beta(\sigma-1))} g_{\infty}^{Y} .
$$

and $\hat{z}_{\infty}^{A}, g_{\infty}^{N}$ and $G_{\infty}$ are uniquely given by the intersection of three equations

\section{Share of automated firms :}

$$
G_{\infty}=\frac{\eta\left(G_{\infty}^{\chi} \hat{z}_{\infty}^{A}\right)^{\kappa}}{g_{\infty}^{N}+\eta\left(G_{\infty}^{\chi} \hat{z}_{\infty}^{A}\right)^{\kappa}}
$$

$$
\text { Free Entry : } \frac{1}{\gamma}=\frac{\hat{z}_{\infty}^{A}\left(\frac{1}{\kappa}-1\right)}{\left(\rho+\left(\theta-1+\psi^{-1}\right) \psi g_{\infty}^{N}\right)} \text {, }
$$

\section{Automation :}

$\widehat{\pi}_{\infty}:$ normalized profits of automated firms

$$
=\frac{\overbrace{\left(\frac{\beta^{\beta}(\sigma-1)^{\beta}}{\sigma}\right)^{\frac{1}{1-\beta}} H G_{\infty}^{\psi-1} \varphi^{\mu \psi}}^{(\underbrace{\left(\rho+\left(\theta-1+\psi^{-1}\right) \psi g_{\infty}^{N}\right)}_{\widehat{r}_{\infty}: \text { normalized interest rate }}}-}{-}
$$

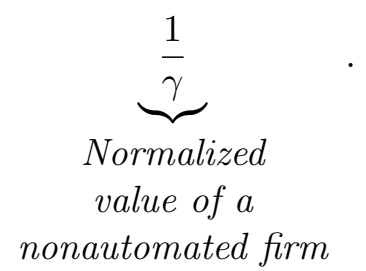

inverse marginal

intensity of automation nonautomated firm

\footnotetext{
${ }^{17}$ To ensure the existence of an asymptotic steady-state with positive growth and meaningful comparative statics we only require that $\theta>1-\psi^{-1}$. However, for $1-\psi^{-1}<\theta<1$, an additional restriction on parameters must be met to satisfy the transversality condition. To simplify exposition and since this is the empirically relevant case we focus our analysis on $\theta \geq 1$.

${ }^{18}$ The normalization of the automation function, $\eta\left(z_{t}^{A} G_{t}^{\chi} N_{t}^{1-\psi}\right)$, by $G_{t}^{\chi}$ implies that investments in innovation for automation are strategic complements for intermediate input producers. This gives rise to potentially multiple equilibria. Though, this could itself be interesting, we here restrict attention to parameter specifications that ensure unique asymptotic equilibria. This would naturally be the case for $\chi=0$, but either $\psi>1-\chi \kappa$ or $\left.\frac{\gamma^{\kappa} \rho^{1-\kappa}(1-\kappa)^{\kappa}}{\eta \kappa^{\kappa}}<((\theta-1) \psi+1) \frac{1-\chi \kappa+\psi(1-\kappa)}{1-\chi \kappa-\psi}\right)$ are sufficient conditions as well.

${ }^{19}$ With two state variables $(N$ and $G$ ) saddle path stability requires exactly two eigenvalues with positive real parts. We examine numerically the set of parameters that arises from the product of sets of $\beta \in[0.1,0.9]$, $\sigma \in[1.5,6], \gamma \in[0.8,1.2], \eta \in[0.1,4], \kappa \in[0.2,0.5], \chi \in[0,1], \tilde{\varphi} \in[1.25,2.3], \epsilon \in(1, \infty)$ with $H=L=0.5$ and $\rho=0.02$ when parameters satisfies condition (23), $\mu<1$ and give rise to a unique steady state. In all cases, there are two negative eigenvalues. We are further examining the issue numerically and algebraically.
} 
Proof. See Appendix X.

From now on, we restrict attention to the case where parameters are such that the asymptotic steady-state is unique and saddle-path stable (our numerical analysis shows that this is not a strong restriction on parameters, see Appendix $\mathrm{X}$ ). Though the model does not feature a balanced growth path in all variables, the growth rate of high-skill wages equals that of $Y_{t}$ on the entire transition path. Total consumption $C_{t}$ and total R\&D expenditures $N_{t}\left(1-G_{t}\right) z_{t}+Z_{t}^{D}$ are asymptotically constant fractions of $Y_{t}$ as is spending on machines. Low-skill wages grow at a lower rate and their asymptotic factor share is zero. This happens as a consequence of increasing low-skill wages which implies a continuous substitution away from low-skill workers for automated firms and a decreasing market share for automated firms.

For given $\left(\hat{z}_{\infty}^{A}, g_{\infty}^{N}\right)$, equation (25) defines a unique level for the asymptotic share of automated firms, $G_{\infty}$, which is increasing in the investment in automation $\hat{z}_{\infty}^{A}$ and decreasing in the asymptotic growth rate in new products $g_{\infty}^{N}$. Given this dependence of $G_{\infty}$, the asymptotic steady state is characterized by the intersection of the Automation and Free Entry conditions in $\left(\hat{z}_{\infty}^{A}, g_{\infty}^{N}\right)$ space. Consider first the free entry condition, the right hand side of equation (26) is the asymptotic (normalized) value of an non-automated firm which has an expected flow value of $-\hat{z}_{\infty}^{A}+\eta\left(G_{\infty} \hat{z}_{\infty}^{A}\right)^{\kappa}\left(\hat{V}_{\infty}^{A}-1 / \gamma\right)=-\hat{z}_{\infty}^{A}+\hat{z}_{\infty}^{A} / \kappa$. The free entry condition requires a positive slope between $\hat{z}_{\infty}^{A}$ and $g_{\infty}^{N}$ as a higher $\hat{z}_{\infty}^{A}$ must come from a higher value of an automated firm which increases the value of a non-automated firm. With free entry in horizontal innovations this increases the growth rate of the economy, $g_{\infty}^{N}$ which increases the interest rate, reduces the value of a new non-automated firm and ensures zero profits of horizontal innovation. Next, consider the automation condition. It is derived from the incentive for a non-automated firm to spend resources on automation as given by equation (14). Using the normalization this can be written as $\left(\hat{z}_{\infty}^{A}\right)^{1-\kappa} /\left(\eta G_{\infty}^{\chi \kappa} \kappa\right)=\left(\hat{V}_{\infty}^{A}-\hat{V}_{\infty}^{N}\right)$, which by suitable substitution can be written as the Automation condition. The condition makes it clear that the incentive to automate is a strictly positive monotonic function of the difference between the (normalized) value of an automated firm and that of a non-automated firm.

To understand the comparative statics with respect to the automation technology and the horizontal innovation technology, it is convenient to first analyze the specific case where $\psi=1$ and $\chi=0$, so that the free-entry condition and automation conditions are independent of the asymptotic share of automated firms and the automation condition and free entry condition are sufficient to describe the equilibrium. Figure 2 a plots these two in $\left(\hat{z}_{\infty}^{A}, g_{\infty}^{N}\right)$. The free entry condition remains unchanged and requires a positive slope. The Automation condition is now unambiguously downward sloping: a higher $g_{\infty}^{N}$ gives a higher interest rate, which reduces the present discounted value of an automated firm and thereby the incentive to invest in automation.

Now, consider first an increase in the productivity of the automation technology $\eta$, which leaves the free entry condition unchanged but pushes out the Automation condition. Lower cost of automation encourages higher expenditures on automation, $\hat{z}_{\infty}^{A}$, which in turn increases the value of being non-automated and encourages more horizontal innovation: both $g_{\infty}^{N}$ and $z_{\infty}^{A}$ increase. The consequences of an increase in the horizontal innovation technology, $\gamma$, are demonstrated in figure $2 \mathrm{~b}$. An increase in $\gamma$ reduces the value of a non-automated firm and encourages further innovation in automation, pushing out the Automation condition. The free entry condition moves to the right as more efficient entry increases the interest rate. Consequently, the growth rate of the economy increases, and one can show that $\hat{z}_{\infty}^{A}$ must decrease.

When $\psi \neq 1$ or $\chi \neq 0$, the problem is more complicated because the asymptotic share 


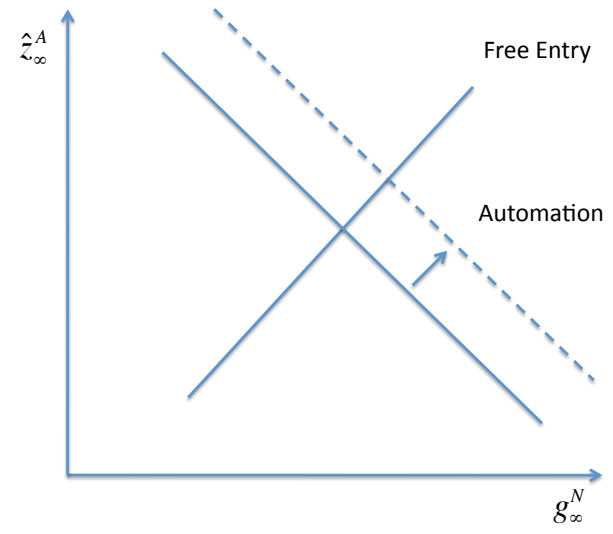

(a) The Asymptotic Steady State and an Increase in Productivity of Automation Technology $\eta$. The Automation condition is negatively sloped: A higher growth rate of the economy, $g_{\infty}^{N}$, increases the interest rate and reduces the incentive to automate an existing non-automated product. The Free Entry condition is positively sloped: Higher expenditures on innovation in automation, $\hat{z}_{\infty}^{A}$, must be associated with higher expected gains from automation and a higher incentive to enter. This is offset by higher $g_{\infty}^{N}$.

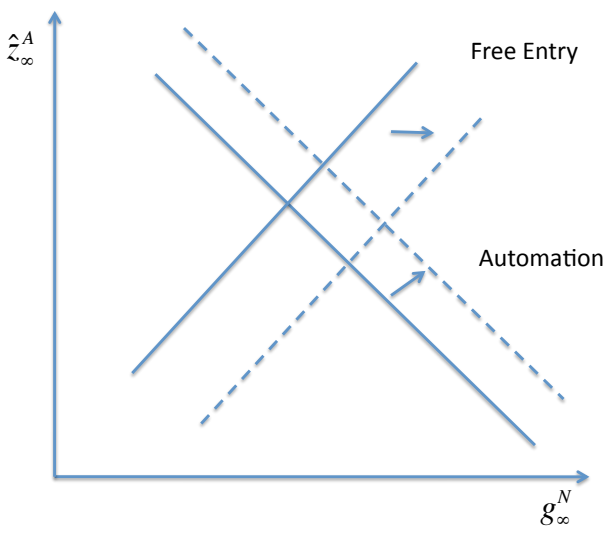

(b) An Improvement in Productivity of Horizontal Innovation Technology $\gamma$. A higher $\gamma$ reduces the value of non-automated firms, increases the incentive to automate and pushes the Automation condition to the right. It further increases the inflow of new products and pushes the Free Entry condition to the right. As a consequence $g_{\infty}^{N}$ increases and $\hat{z}_{\infty}^{A}$ drops.

Figure 2: Asymptotic Steady State for special case of $\psi=1$ and $\chi=0$ 
of automated firms enter the automation equation through its impact on the productivity of the automation technology and/or through its impact on the profits of automated firms. As a result, the automation curve is not necessarily downward sloping and to understand the intuition, it is better to look directly at the automation equation but considering $g_{\infty}^{N}$ as a function of $\hat{z}_{\infty}^{A}$ defined by the free-entry equation (26), and $G_{\infty}$ as a decreasing function of $\hat{z}_{\infty}^{A}$ implicitly defined by the share of automated firms and the free-entry equations (25) and (26). ${ }^{20}$ Then it can be shown that a change in parameters that increases the right-hand side of this modified automation condition increases the equilibrium value of $\hat{z}_{\infty}^{A} \cdot{ }^{21}$ At given $\hat{z}_{\infty}^{A}$, a higher productivity of the automation technology $\eta$ further increases the effective productivity of the automation technology $\left(\eta G_{\infty}^{\chi \kappa}\right)$ through its positive impact on the asymptotic share of automated firms for $\chi \neq 0$. Moreover, the increase in the asymptotic share of automated firms, increases the profits of firms if $\psi>1$, but decreases them if $\psi<1$. Higher profits tend to increase automation expenditures (it increases the right-hand side of the automation equation), so that the positive impact of $\eta$ on $\widehat{z}_{\infty}^{A}$ is reinforced when $\psi>1$ and mitigated otherwise. Nevertheless, it is possible to show that this mitigation effect is never the dominant one, so that $\widehat{z}_{\infty}$ and $g_{\infty}^{N}$ are always increasing in the productivity of the automation technology $\eta$.

For given $\widehat{z}_{\infty}$ an increase in $\gamma$ lowers the asymptotic share of automated firms (as there are more new firms created every instant). When $\chi \neq 0$, this has a negative impact on the effective productivity of the automation technology $\left(\eta G_{\infty}^{\chi \kappa}\right)$, which tends to reduce $\widehat{z}_{\infty}^{A}$. In addition, for $\psi>1$, this leads to lower profits for automated firms which lowers the intensity of automation $\widehat{z}_{\infty}$ (and the opposite when $\psi<1$ ). In fact, the intensity of automation may decrease sufficiently that the growth rate $g_{\infty}^{N}$ decreases. This latter scenario is only possible if these two effects are sufficiently large, in particular, it requires that $\psi+\chi>1 / \kappa \cdot{ }^{22}$ The interpretation of this counter-intuitive result is the following: a higher productivity for horizontal innovation reduces the incentive to automate and therefore the value of a new variety so much that the intensity of horizontal innovation decreases sufficiently for the growth rate in new products to go down. To summarize, and taking into account that the asymptotic growth rate of the economy $g_{\infty}^{Y}=\psi g_{\infty}^{N}$, we have:

Proposition 4. An increase in the productivity of the automation technology $\eta$ increases the asymptotic expenditures on automation $\widehat{z}_{\infty}^{A}$ and the asymptotic growth of the economy $g_{\infty}^{Y}$. An increase in the productivity of the horizontal innovation technology decreases the asymptotic intensity of automation $\widehat{z}_{\infty}^{A}$ if $\psi \geq 1-\chi \kappa$ and increases the growth rate of the economy $g_{\infty}^{Y}$ if $\psi \leq(1-\chi \kappa) / \kappa$.

\section{Transitional Dynamics}

In the following we illustrate the transitional dynamics of the system through simulation methods (at the moment we choose 'reasonable' parameters and we will calibrate the model in the

\footnotetext{
${ }^{20}$ Substitute the Free Entry condition (26) into the equation for $G_{\infty}$ to get $G_{\infty}=\eta\left(G_{\infty}^{\chi} \hat{z}_{\infty}^{A}\right)^{\kappa} /\left(\frac{\gamma \hat{z}_{\infty}^{A}\left(\frac{1}{\kappa}-1\right)-\rho}{(\theta-1) \psi+1}+\right.$ $\left.\eta\left(G_{\infty}^{\chi} \hat{z}_{\infty}^{A}\right)^{\kappa}\right)$, which is decreasing in $\hat{z}_{\infty}^{A}$ for $\kappa<1$.

${ }^{21}$ Moving the normalized value of a non-automated firm $1 / \gamma$ to the left-hand side, and then dividing the left-hand side by the right-hand side defines a function of $\hat{z}_{\infty}^{A}$, which can be shown to be increasing around steady-state.

${ }^{22}$ Note that this is a necessary condition but not a sufficient one.
} 
future). ${ }^{23}$ Our goal is to capture a shift from little to extensive reliance on machines and automation. We therefore choose a low initial level of automation $G_{0}=0.005$ (recall that our normalization of the automation technology does not allow us to set $G_{0}=0$ for $\chi>0$ ) and a low initial mass of intermediate inputs $N_{0}=10$ which gives an initial low-skill wage of 1 . The parameters of the model are as follows

Table 1: Base-line Parameter Specification

\begin{tabular}{|c|c|c|c|c|c|c|c|c|c|c|c|}
\hline$\sigma$ & $\epsilon$ & $\beta$ & $H$ & $L$ & $\theta$ & $\eta$ & $\kappa$ & $\tilde{\varphi}$ & $\rho$ & $\chi$ & $\gamma$ \\
\hline \hline 3 & 4 & 0.5 & 0.5 & 0.5 & 1 & 0.21 & 0.5 & 1.78 & 0.02 & 1 & 1 \\
\hline
\end{tabular}

Total stock of labor is 1 and we set $H=L=1 / 2$ and $\beta=1 / 2$ such that absent automation low-skill and high-skill workers would be symmetric. We set $\sigma=3$ to capture an initial share of labor of $2 / 3$. We set $\tilde{\varphi}=1.78$ which gives initial relative profits of an automated firm of 2.4 times that of an non-automated firm. The productivity of horizontal and automation innovations, $\gamma=1$ and $\eta=0.21$, are chosen to match an asymptotic growth rate of $Y$ of 2 per cent and a an asymptotic share of automated products of $G_{\infty}=2 / 3$. We set $\theta=1$ and $\rho=0.02$ which returns a long-run interest rate of $4 \%$. Finally, we set $\chi=1, \kappa=1 / 2$, and $\epsilon=4$. This gives a $\psi=1$ and $\beta /[(1-\beta)(\epsilon-1)]=1 / 3$, which means that for Proposition 1 we are in the (iii) case.

The transitional dynamics are shown in Figure 3. These can be split into three distinct phases. First, little investment in automation has taken place, the stock of intermediate inputs is low, and wages are low. During this phase there is little automation and both low-skill and high-skill wages follow the growth path of the economy as a whole, which is initially just below 2.5 per cent (The Southwest and Northwest panels of Figure 3). Both low-skill and high-skill workers retain an almost constant share of GDP and total labor share remains above 60 per cent for more than 80 years (with machines being an intermediate input in production we define $G D P=Y-X)$.

As the economy grows it moves into the second phase where the increasing stock of automated products and the higher low-skill wages increase the incentive for non-automated firms to automate and for already automated firms to substitute machines for low-skill workers. As can be seen from the Southeast panel of Figure 3 the expenditures on innovation in automation gradually increases from just above zero to its steady state level of 8 per cent of GDP. As $G$ increases, following the initial increase in automation expenditures, the growth rate of low-skill workers declines. In this simulation it reaches a minimum of just above zero after 80 years (though, the growth rate is positive for this simulation, it is easy to find parameter values for which the growth rate of low-skill wages can temporarily become negative). During this period the increased use of automation is sufficient to (almost) cancel the positive effects on low-skill wages from a growing stock of intermediate inputs. High-skill wages continue to grow at the rate of the economy and the skill-premium increases from parity to around 2 after 100 years (Since $H=L$, the skill-premium can be found by dividing the high-skill factor share with the low-skill factor share). The factor share of GDP accruing to high-skill workers increases from the second phase on. This is a consequence of high-skill workers retaining a constant share of $Y$; the increased use of intermediate inputs - which do not count towards GDP — implies a

\footnotetext{
${ }^{23}$ We employ the so-called "relaxation" algorithm for solving systems of discretized differential equations (Trimborn, Koch and Steger, 2008). See Appendix X for details.
} 

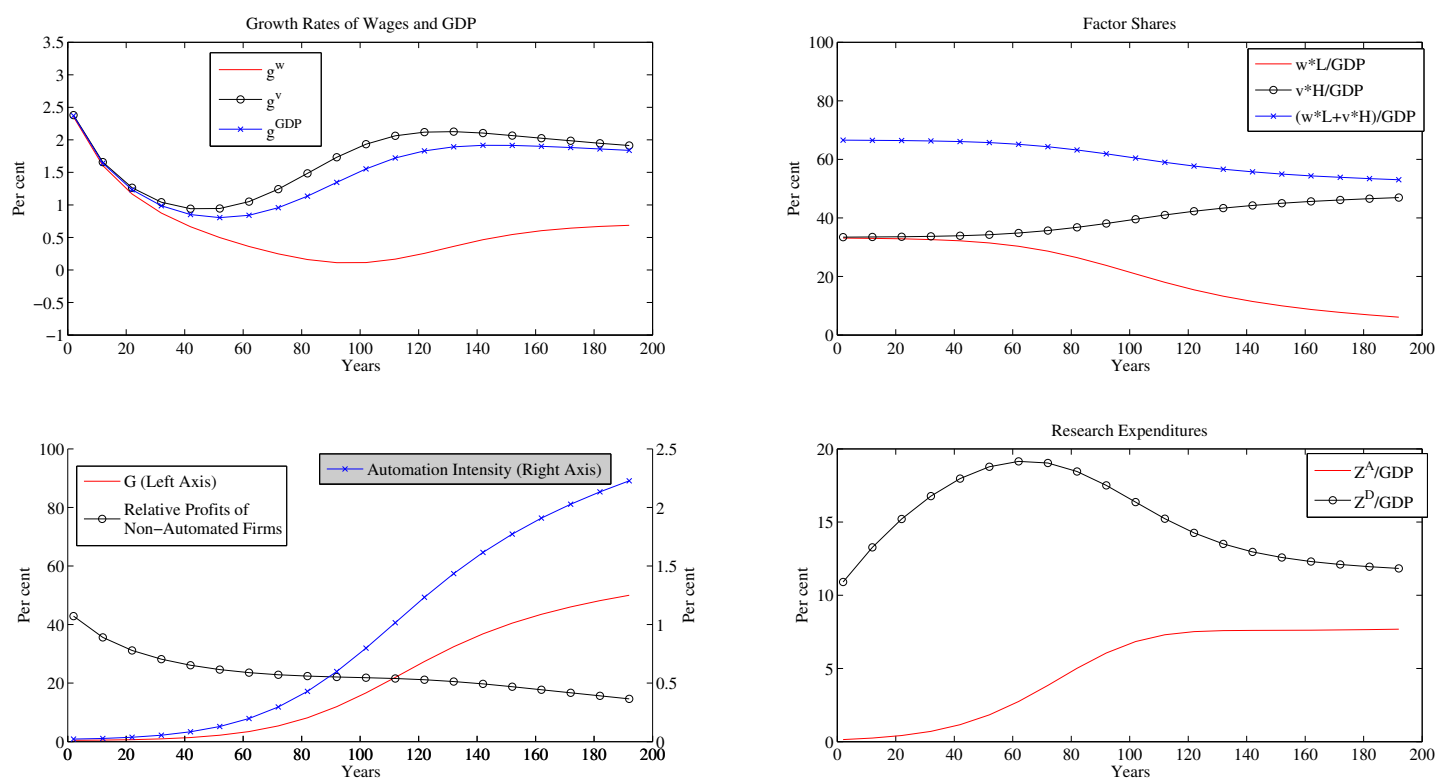

Figure 3: Transitional Dynamics for Baseline Parameters

decreasing GDP $/ Y$. As a consequence total labor share of GDP drops only marginally over the entire period, though low-skill workers share of labor continuously approach its asymptotic level of zero. This is consistent with recent evidence that has seen a long period of constant labor share of GDP, but a recent drop. Karabarbounis and Neiman (2013) find a global reduction of 5 percentage points in labor's share of corporate gross value added over the past 35 years.

Finally, as the economy approaches its new steady state, with $G$ being (almost) constant, the results of Proposition 2 hold and the asymptotic growth rate of low-skill wages must be positive. The combination of an asymptotic growth rate of the economy of 2 per cent and the parameter choices of $\beta$ and $\sigma$ implies an asymptotic growth rate of low-skill wages of 1 per cent $(=2 \% /(1+\beta(\sigma-1)))$. Hence, the model mirrors the path of income inequality in the US of an acceleration from the early 1980s to the mid 1990s followed by a deceleration thereafter. Note, that this happens in spite of continuously increasing automation intensity and spending as seen by the lower panels of figure 3. The fact that there is no direct one-toone link between the automation intensity and the skill-bias of technical change speaks to the current debate over the usefulness of SBTC in explaining the patterns of inequality. Both Card and DiNardo (2002) and Lemieux (2006) argue that the combination of a deceleration in the growth of inequality along with continuous growth in spending on computers is problematic for the SBTC framework, whereas the present model suggests that the change in the intensity of automation could be a more important driver of inequality.

We further analyze the sources of economic growth, by doing a growth decomposition of low-skill wages and GDP. Note, that at each point in time, we can write low-skill wages as a function of $N_{t}$ and $G_{t}$ from equation (9): $w_{t}=f\left(N_{t}, G_{t}\right)$. Differentiating with respect to time 

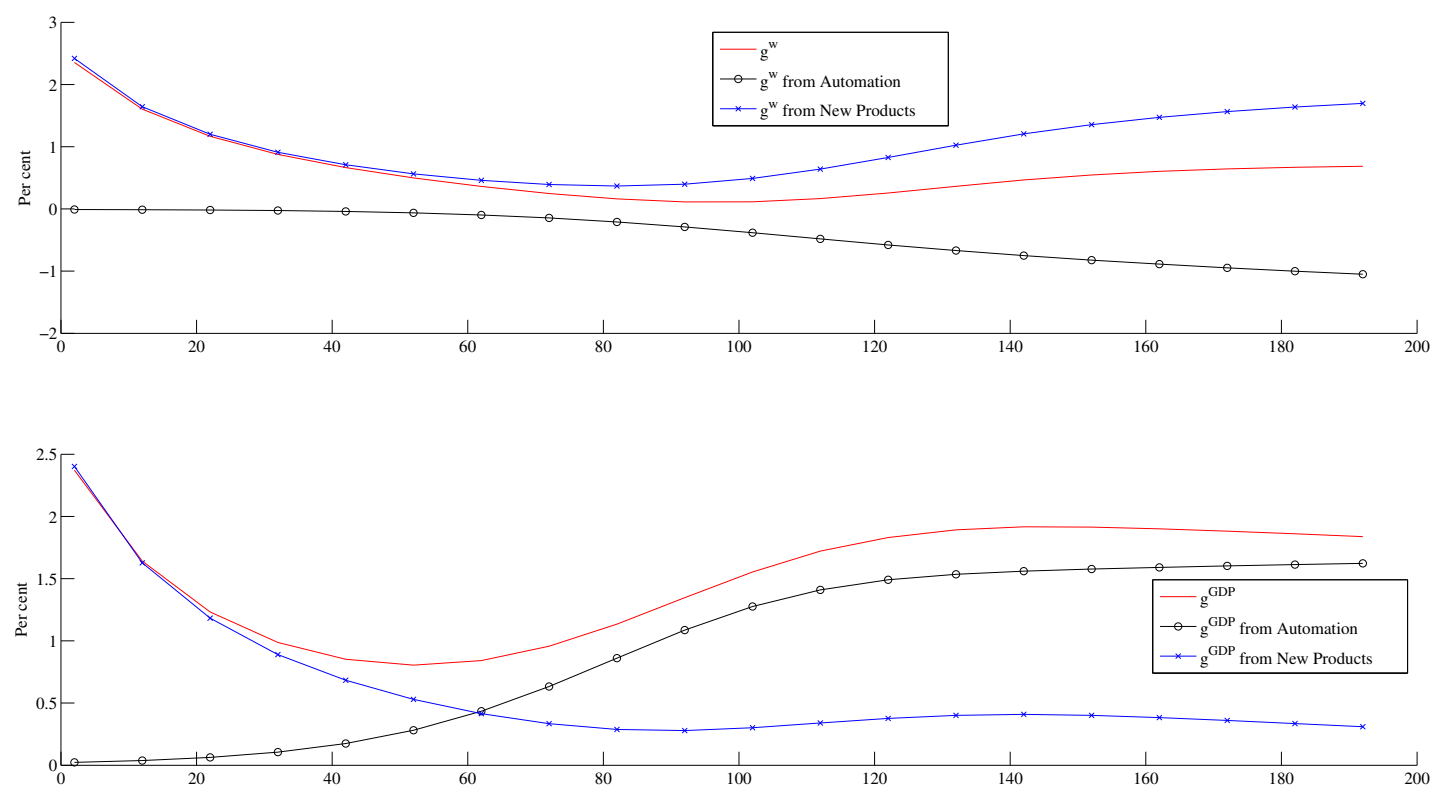

Figure 4: Growth Decomposition for Low-skill Wages and GDP: The top panel shows the contribution to growth in low-skill wages from the instantaneous expenditures on automation, $\hat{z}_{t}^{A}$, and horizontal growth, $g_{t}^{N}$. The lower panel does the same decomposition for the growth rate in GDP.

and using equation (17) gives:

$$
g_{t}^{w}=\left(\frac{N_{t}}{w_{t}} \frac{\partial f}{\partial N}-\frac{G_{t}}{w_{t}} \frac{\partial f}{\partial G}\right) g_{t}^{N}+\frac{G_{t}}{w_{t}} \frac{\partial f}{\partial G}\left(\eta\left(G_{t}^{\chi}\right)^{\kappa}\left(1-G_{t}\right) / G_{t}\right)\left(\hat{z}_{t}^{A}\right)^{\kappa}
$$

where the first term is the instantaneous growth in low-skill wages arising from a positive growth rate in the stock of intermediate inputs, and the second term is correspondingly the contribution from positive automation research. An analogous expression can be derived for GDP. Note, that the interpretation of these two terms is the change in growth from an instantaneous drop in the corresponding research intensity, not the long-term consequences of stopping innovation in one type of innovation. As emphasized in the discussion after equation (23), economic growth would eventually stop if either innovation stopped. Figure 4 below plots $g_{t}^{w}$ and $g_{t}^{G D P}$ along with the corresponding growth decomposition.

Reflecting the initial low expenditures on automation, growth in both GDP and low-skill wages is driven by the introduction of new products and the contribution from automation is zero. As the size of automation increases the contribution to overall growth shifts from being driven primarily by the introduction of new products to primarily by the automation of old ones. The figure further shows the skill-bias of the two forms of automation. Whereas the introduction of new products only has a marginal impact on the growth rate of the overall economy, and thereby high-skill wages, it has a positive impact on low-skill wages of almost 2 percentage points, implying that horizontal innovation is low-skill biased. ${ }^{24}$ Automation,

\footnotetext{
${ }^{24}$ In this particular simulation horizontal innovation is low-skill biased throughout. Though horizontal inno-
} 

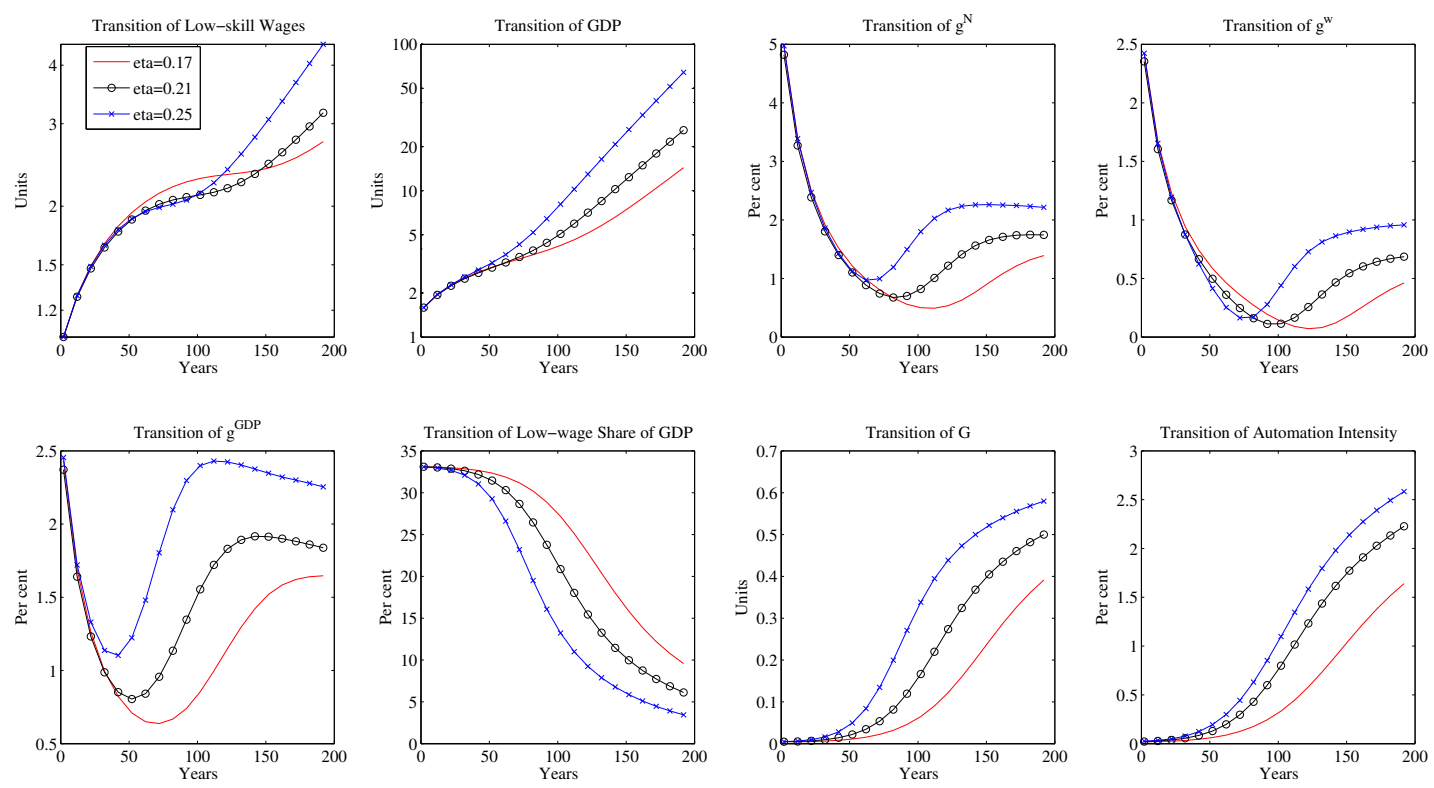

Figure 5: Transitional Dynamics for Varying Automation Productivity, $\eta$

naturally, is high-skill biased.

\subsection{Comparative Statics}

Proposition 4 above made clear that an increase in the automation technology, $\eta$, will increase innovation in both automation and the introduction of new products asymptotically, both increasing the asymptotic growth rate of the economy. In the following, we consider the consequences for the transitional dynamics by plotting the cases $\eta=0.17$ and $\eta=0.25$, in addition to the baseline value of $\eta=0.21$ in Figure 5. It is immediately clear that higher $\eta$ leads to higher automation intensity and consequently higher inflow of new products both of which guarantee a higher transitional path of GDP. However, higher automation intensity implies a more rapid and dramatic shift into 'Phase 2' in which low-skill wages suffer from higher automation. Hence, low-skill wages as a share of total GDP are unambiguously lower for higher $\eta$, but the path of absolute low-skill wages depends in non-trivial ways on $\eta$. For a temporary period, low-skill wages will be lower for higher $\eta$, though the combination of higher eventual growth rate and Proposition 2 guarantees an eventual higher low-skill wages.

In addition we show the comparative statics for an analogous variation of the productivity of horizontal innovation. We display $\gamma=0.95$ and $\gamma=1.05$ in addition to its initial value of $\gamma=1$. Figure 6 demonstrates how the growth rate of the economy is higher for higher $\gamma$. This results in a higher growth in low-skill wages. The low-skill labor share of total GDP is lower for higher $\gamma$. This is a consequence of the higher absolute low-skill wages - which causes a substitution towards machines for already automated firms - and an almost unchanged fraction of firms which are automated.

vation is always low-skill biased for sufficiently large $w$, it is not generally the case. 

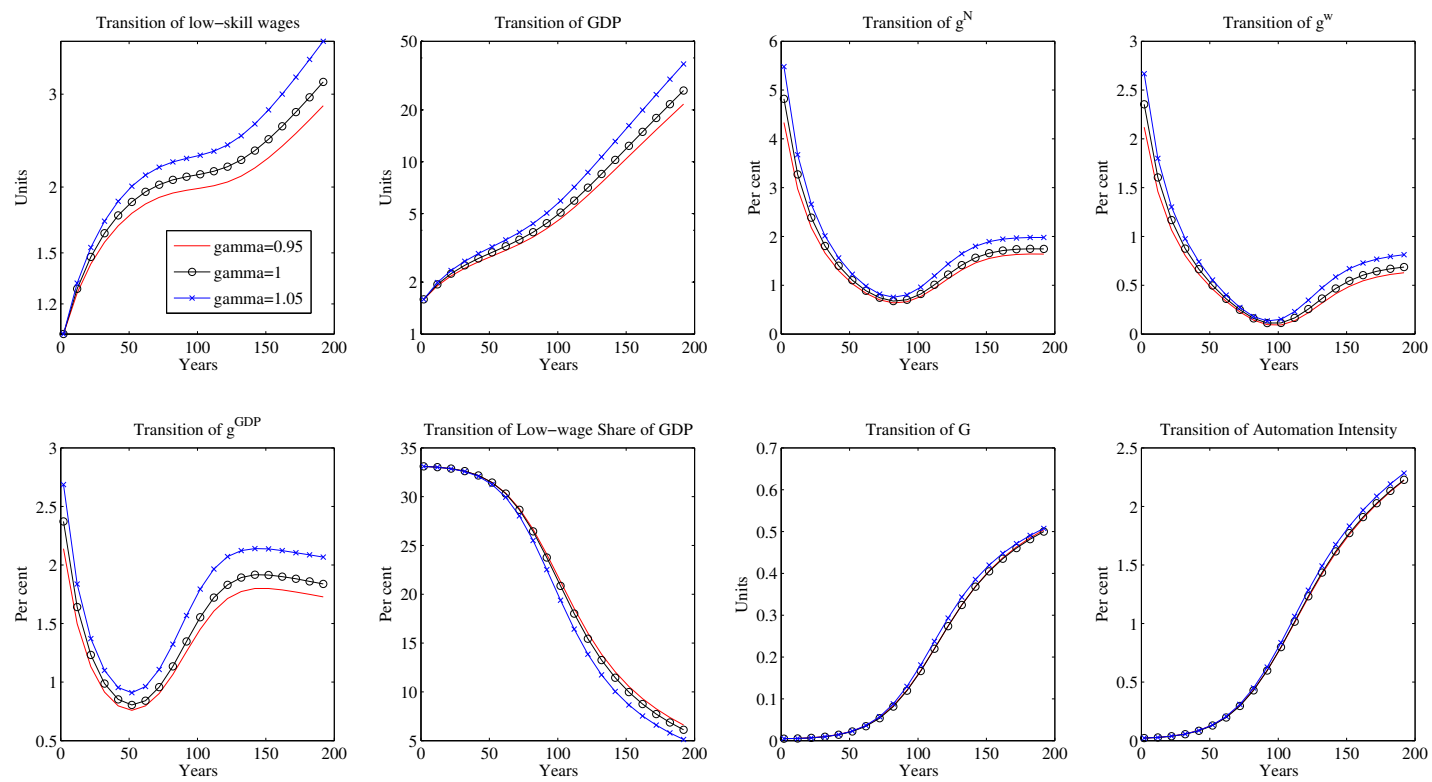

Figure 6: Transitional Dynamics for Varying Productivity of Horizontal Innovation, $\gamma$ :

\section{Middle-Skill Workers and Wage Polarization}

Autor, Katz, and Kearney (2006) argue that a more detailed look at the income distribution is necessary to understand the effects of SBTC, including the apparent deceleration of income inequality from the mid 90s. They show that the evolution of the U.S. wage distribution shows distinct patterns in the 1970s and 1980s compared with those of the following decades. In the first period wage inequality is uniformly increasing and those with the highest earnings see the highest increases, whereas from the mid to late 1980s the lowest wage increases is to be found in the middle-income groups with the highest and lowest experiences higher relative wage increases. They and Autor and Dorn (2013) conjecture that these workers perform 'cognitive routine' tasks which are more easily replaced by machines.

The preceding model suggests a related, but distinct explanation: Automating the tasks performed by middle-skill workers is not easier, but more difficult and therefore happens later. Hence, before 1990 and for most of the 20th century low-skill workers were in the process of being replaced by automation as semi-automated factories, mechanical farming, household appliances etc were increasingly used. Now computers are powerful enough to replace middleskill workers and in the period since 1990 it has mostly been middle-skill workers who find themselves being replaced by computers, algorithms etc.

To make this hypothesis precise we must introduce a mass $M$ of middle-skill worker into the model. We think of these workers as being sequentially 'ranked' such that high-skill workers can perform all tasks, middle-skill workers can perform middle-skill tasks and low-skill tasks, and low-skill workers can perform only low-skill tasks. All newly introduced intermediate products continue to be non-automated, but there is an exogenous probability $\delta$ that it will require low-skill and high-skill workers as described before and a probability $1-\delta$ that it will 
require middle-skill workers and high-skill workers without the need for low-skill workers. The extension of the individual production is therefore:

$$
\begin{gathered}
y_{L}(i)=\left[l(i)^{\frac{\epsilon-1}{\epsilon}}+\alpha(i)\left(\tilde{\varphi}_{L} x(i)\right)^{\frac{\epsilon-1}{\epsilon}}\right]^{\frac{\epsilon \beta}{\epsilon-1}} h(i)^{1-\beta}, \\
y_{M}(i)=\left[m(i)^{\frac{\epsilon-1}{\epsilon}}+\alpha(i)\left(\tilde{\varphi}_{M} x(i)\right)^{\frac{\epsilon-1}{\epsilon}}\right]^{\frac{\epsilon \beta}{\epsilon-1}} h(i)^{1-\beta},
\end{gathered}
$$

where $y_{L}(i)$ and $y_{M}(i)$ are the production of intermediate input producers who employ low-skill workers and middle-skill workers, respectively, and $m(i)$ is the use of middle-skill workers by a firm of the latter type. $\tilde{\varphi}_{L}$ and $\tilde{\varphi}_{M}$ are the productivity of machines that replace low-skill workers and middle-skill workers, respectively. The mass of intermediate input producers who use low-skill workers is $\delta N$ with the remaining, $(1-\delta) N$, using middle-skill workers. ${ }^{25}$ The final good continues to be produced competitively by a CES aggregator of all intermediate inputs and machines for either type of intermediate input producer are produced one-for-one with the final good keeping a constant price of 1 . The shares of automated products, $G_{L}$ and $G_{M}$ will in general differ.

Both types of producers continue to have access to an automation technology as before, but we allow the productivity to differ, such that automation happens with intensity $\eta_{L}\left(z_{L, t}^{A} G_{L, t}^{\chi} N_{t}^{1-\psi}\right)$ for firms employing low-skill workers and $\eta_{M}\left(z_{M, t}^{A} G_{M, t}^{\chi} N_{t}^{1-\psi}\right)$ for those employing middle-skill workers. Denote wages for low-skill and middle-skill workers by $w_{L}$ and $w_{M}$, respectively, and the corresponding normalized values $\omega_{L}$ and $\omega_{M}$. We show in Appendix $\mathrm{X}$ that analogous to section 4 we can write this as a system of 6 differential equations for $\left(n_{t}, G_{L, t}, G_{M, t}, \hat{z}_{L, t}^{A}, \hat{z}_{M, t}^{A}, \hat{C}_{t}\right)$ with 4 auxiliary variables $\left(\hat{\pi}_{L, t}, \omega_{L, t}, \omega_{M, t}, g_{t}^{N}\right)$, where $\hat{\pi}_{L, t}$ is the normalized profits for an automated firm using low-skill workers. We then show that analogous to Proposition 3, the following lemma holds

Lemma 3. Consider the model with middle-skill workers as outlined above for which the asymptotic steady-state is unique and saddle-path stable. ${ }^{26}$ For an initial pair $\left(N_{t}, G_{L, t_{0}}, G_{M, t_{0}}\right) \in$ $(0, \infty) \times(0,1] \times(0,1]$ (with $G_{L, t_{0}}, G_{M, t_{0}}>0$ if $\left.\chi>0\right)$ sufficiently close to the asymptotic steady-state, the model features a unique equilibrium. It holds that high-skill wages, $v_{t}$, and $Y_{t}$ grow at the same rate:

$$
g_{t}^{v}=g_{t}^{Y}, \text { for all } t .
$$

Asymptotically, so does total spending on each form of automation, $\delta N_{t}\left(1-G_{L, t}\right) z_{L, t}^{A}$ and $(1-\delta) N_{t}\left(1-G_{M, t}\right) z_{M, t}^{A}$, total spending on innovation of new products $Z_{t}^{D}$, and consumption, $C_{t}$. This growth rate is proportional to the growth rate of $N$

$$
g_{\infty}^{Y}=\psi g_{\infty}^{N}
$$

Both low-skill and middle-skill wages grow asymptotically as

$$
g_{\infty}^{w_{L}}=g_{\infty}^{w_{M}}=\frac{1}{1+\beta(\sigma-1)} g_{\infty}^{Y}
$$

\footnotetext{
${ }^{25}$ Naturally, a more realistic model would allow all products to be produced by all factors. That would make the analysis substantially more complicated without altering the underlying argument.

${ }^{26}$ This is the case for the set of parameters chosen for the simulation. We have not yet established more general conditions.
} 
Proof. In Appendix X.

The Lemma gives the direct extension of Proposition 3. Both low-skill and middle-skill wages must grow asymptotically, though at less than the economy for reasons that directly mirror previous discussions. We now turn to the transitional dynamics. To emphasize the role of distinct innovation technologies, we choose $\delta=1 / 2$ and keep parameters as before except that the productivity of the automation technology for middle-skill workers is given by $\eta_{M}=0.19$ and $\eta_{L}$ continues to be 0.21 . We also set $L=M=0.25$ to keep the mass of workers that can be replaced by machines at 0.5 . The overall picture is similar to that of Figure 3 , but with distinct paths for low-skill and middle-skill wages as shown in figure 7 . The crucial difference is that the less productive automation technology implies a slower adaptation of automation in firms employing middle-skill workers. With a substantially faster increase in $G_{L}$ than in $G_{M}$ the dampening effects on low-skill wages from increasing automation is more pronounced for decades and they grow slower than both high-skill wages and middle-skill wages. Though slower there is continuous automation of firms employing middle-skill workers. However, after 165 years automation for firms employing low-skill workers tapers off, but continues for firms employing middle-skill workers. This causes a shift in the relative growth rates of wages and for the rest of the simulation low-skill wages grow faster than that of middle-skill wages as they both approach the asymptotic growth rates of 1 per cent. Note, that at all points in time $v_{t} \geq w_{M, t} \geq w_{L, t}$ so no group has an incentive to be employed beneath its skill level.

The same point is made slightly differently in the Southeast panel of Figure 7. This panel replicates the analogue of Figure 2 in Autor, Katz and Kearney (2006) which shows a monotone spreading out of the income distribution for 1973-1988 (corresponding to the period 146-166 years), but a wage growth polarization where middle-income earners see the slowest growth rate from 1988-2004 (corresponding to the period 166-186 years).

Our assumption that automation is intrinsically easier for intermediate inputs hiring lowskill workers than for those hiring middle-skill workers $\left(\eta_{M}<\eta_{L}\right)$ may seem at odds with empirical papers which argue that automation now predominantly hurts middle-skill workers. Our model emphasizes that the intensity of automation and the technological possibilities for automation are different concepts, since the intensity of automation does not depend only on its cost but also on its benefit. Hence, in the last phase of our simulation, more middle-skill worker products get automated than low-skill worker products, even though automating lowskill products is less costly. Yet, some papers argue that the technological opportunities for automation are today lower for low-skill workers than for middle-skill workers. This is easy to reconcile with our model if we assume that for both low-skill and middle-skill products, a common fixed share can never be automated (or have a much lower automation productivity, identical for both types of products). In this case, the share of low-skill workers hired in the products that can never be automated will be larger than the corresponding share for middleskill workers (since a higher share of low-skill products will have been automated), and as a result, it may be on average easier to automate a product hiring middle-skill workers than one hiring low-skill workers.

\section{Extensions}

The baseline model featured exogenous stocks of low- and high-skill labor and allowed the final good to be used for both the production of machines and consumption. In the following, we 

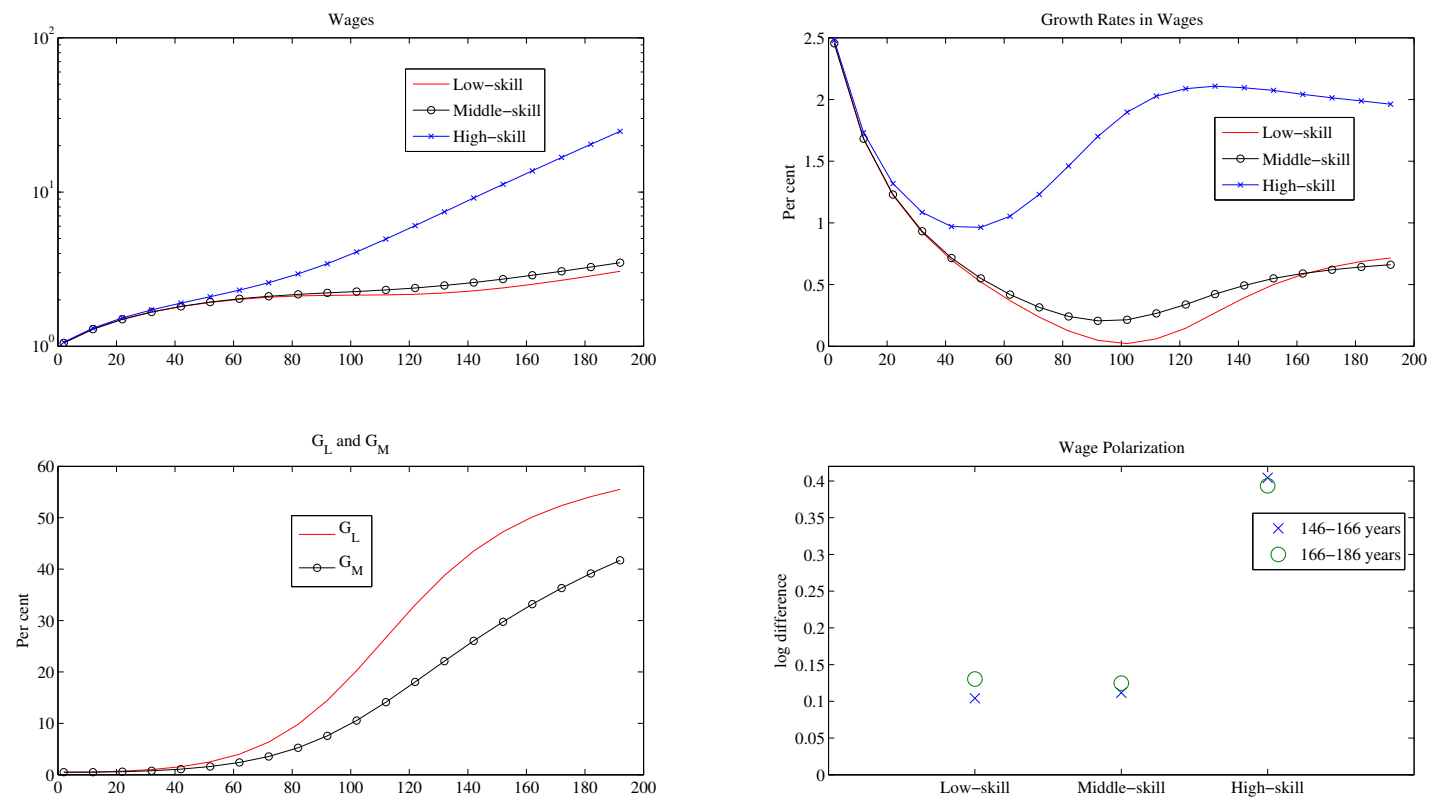

Figure 7: Transitional Dynamics with Middle-Skill Workers

generalize the model to allow for, respectively, i) different production technologies for machines and the consumption good and ii) workers with heterogeneous abilities of different skills and an endogenous choice of where to supply skills. For expositional clarity both extensions are made for the specification without middle-skill workers.

\subsection{Alternative Production Technology for Machines}

The assumption of identical production technologies for consumption and machines imposes a constant real price of machines. For this setting, Proposition 2 gives the general conditions under which the real wages of low-skill workers must increase asymptotically. As shown in Nordhaus (2007) the price of computing power has dropped dramatically over the past 50 years. The declining real price of computers/capital is central to the theories of Krusell et. al. (2000), Autor and Dorn (2013), and Karabarbounis and Neiman (2013).

To allow for declining real prices in machines, we extend the model such that machines and the final good are produced using different technologies. Specifically, let there be two final good sectors, both perfectly competitive employing CES production technology with identical elasticity of substitution, $\sigma$. The output of sector $1, Y$ is used for consumption and research expenditures $Y=C+Z^{A}+Z^{D}$. The output of sector $2, X$, is used solely for machines. The two final good sectors use distinct versions of the same set of intermediate inputs $\mathcal{N}$, where we denote the use of intermediate input $i \in \mathcal{N}$ for sector 1 as $y_{1}(i)$ and that in sector 2 as $y_{2}(i)$. The two versions of intermediate input $i$ are produced by the same intermediate input supplier 
using production technologies that differ only in the weight on high-skill labor:

$$
y_{k}(i)=\left[l_{k}(i)^{\frac{\epsilon-1}{\epsilon}}+\alpha(i)\left(\tilde{\varphi} x_{k}(i)\right)^{\frac{\epsilon-1}{\epsilon}}\right]^{\frac{\epsilon \beta_{k}}{\epsilon-1}} h_{k}(i)^{1-\beta_{k}},
$$

where a subscript, $k=1,2$, refers to the sector where the input is used. Importantly, we assume $\beta_{2} \geq \beta_{1}$, such that the production of machines relies more heavily on machines as inputs in production. Continuing to normalize the price of final good $Y$ to 1 , such that the real price of machines is $p_{t}^{x}$, and allowing for the natural extensions of market clearing conditions, we can derive the following generalization of Proposition 2 (where $\psi_{k}=(\sigma-1)^{-1}\left(1-\beta_{k}\right)^{-1}$ )

Proposition 5. Consider the model above with two final good sectors and take two processes $\left[N_{t}\right]_{t=0}^{\infty}$ and $\left[G_{t}\right]_{t=0}^{\infty}$ where $\left(N_{t}, G_{t}\right) \in(0, \infty) \times[0,1]$ for all $t$. If a strictly positive limit exists for $G_{t}$, then:

$$
\begin{gathered}
g_{\infty}^{p^{x}}=-\psi_{2}\left(\beta_{2}-\beta_{1}\right) g_{\infty}^{N} \\
g_{\infty}^{Y}=\left[\psi_{1}+\psi_{1} \frac{\beta_{1}\left(\beta_{2}-\beta_{1}\right)}{1-\beta_{2}}\right] g_{\infty}^{N},
\end{gathered}
$$

and if $0<\lim _{t \rightarrow \infty} G_{t}<1$ then the asymptotic growth rate of $w_{t}$ is ${ }^{27}$

$$
g_{\infty}^{w}=\frac{1}{1+\beta_{1}(\sigma-1)} \frac{\left[1+\left(1-\left(1-\beta_{1}\right)(\sigma-1)\right) \beta_{1} \frac{\beta_{2}-\beta_{1}}{1-\beta_{2}}\right]}{\left[1+\frac{\beta_{1}\left(\beta_{2}-\beta_{1}\right)}{1-\beta_{2}}\right]} g_{\infty}^{Y} .
$$

Proposition 5 naturally reduces to Proposition 2 for the special case of $\beta_{2}=\beta_{1}$. When $\beta_{2}>\beta_{1}$, the productivity of machine production increases faster than that of the production of $Y$, implying a gradual decline in the real price of machines. For given $g^{N}$, the faster productivity growth of machines has two effects on the real wage of low-skill workers. One can show that the faster growth in the supply of machines will increase the (positive) growth in the relative price of low-skill workers, $w / p^{x}$, but simultaneously, the higher productivity growth of machine production will reduce the real price of machines, $p^{x}$. The combination of these two will always imply that low-skill workers capture a lower share of the growth in $Y$, but the growth rate of low-skill wages need not be negative. Low-skill wages will, however, fall asymptotically for high elasticity of substitution between varieties as higher elasticity of substitution implies an easier substitution away from non-automated products produced relying heavily on low-skill labor to those automated relying more heavily on machines.

\subsection{Heterogeneous Workers and Endogenous Choice of Occupation}

The main text assumed a fixed stock of workers. With a continuously widening wage dispersion between low-skill and high-skill labor, this might seem a restrictive assumption. In the following we allow the labor supply to respond to changes in factor rewards and show that our analysis so far is robust to this addition, although supply effects will help the growth of low-skill wages.

\footnotetext{
${ }^{27}$ If $G_{t}$ tends towards 1 sufficiently fast such that $\lim _{t \rightarrow \infty}\left(1-G_{t}\right) N_{t}^{\psi_{2}(1-\mu) \frac{\epsilon-1}{\epsilon}}$ is finite, then $g_{\infty}^{w}=$ $\frac{1}{\epsilon} \frac{\left[\psi_{1}\left(1+\beta_{1} \frac{\beta_{2}-\beta_{1}}{1-\beta_{2}}\right)-\psi_{2}(\epsilon-1)\left(\beta_{2}-\beta_{1}\right)\right]}{\psi_{1}\left[1+\frac{\beta_{1}\left(\beta_{2}-\beta_{1}\right)}{1-\beta_{2}}\right]} g_{\infty}^{Y} \geq g_{\infty}^{p_{x}}$ whether $\epsilon$ is finite or not. It is clear that there always exists an $\epsilon$ sufficiently high for the real wage of low-skill workers to decline asymptotically.
} 
We adopt a specification of heterogeneous productivity endowments of low-skill and high-skill workers along the lines of Roy (1951). Let there be a unit mass of heterogeneous individuals, indexed by $j \in[0,1]$ each with 2-dimensional endowment. Each is endowed with the ability to supply one unit of low-skill labor and $\Gamma(j)=\frac{(1+\alpha)}{\alpha} j^{1 / \alpha}, \alpha>0$ units of high-skill labor (the exact distribution is of no crucial importance). Workers are thereby ranked in increasing order of their endowment of high-skill abilities on $[0,(1+\alpha) / \alpha]$. The parameter $\alpha$ governs the shape of the ability distribution with $\alpha \rightarrow \infty$ implying equal distribution of skills. We can show the following proposition which generalizes Proposition 2.

Proposition 6. Consider two processes $\left[N_{t}\right]_{t=0}^{\infty}$ and $\left[G_{t}\right]_{t=0}^{\infty}$ where $\left(N_{t}, G_{t}\right) \in(0, \infty) \times[0,1]$ for all $t$, such that $G_{t}$ exists and there is asymptotic positive growth in $N_{t}$. Then if $0<\lim _{t \rightarrow \infty} G_{t}<$ 1 , the asymptotic growth rate of $w_{t}$ is: ${ }^{28}$

$$
g_{\infty}^{w}=\frac{1+\alpha}{1+\alpha+\beta(\sigma-1)} g_{\infty}^{Y},
$$

with

$$
g_{\infty}^{Y}=\psi g_{\infty}^{N}
$$

Proof. See Appendix

At all points in time there exists an indifferent worker $\left(\bar{j}_{t}\right)$ where $w_{t}=(1+\alpha) / \alpha\left(\bar{j}_{t}\right)^{1 / \alpha} v_{t}$, with all $j \leq \bar{j}_{t}$ working as low-skill workers and all $j>\bar{j}_{t}$ working as high-skill workers. This introduces an endogenous supply response as the diverging wages for low- and high-skill workers encourages shifts from low-skill to high-skill jobs. The gradual reduction in supply dampens the relative decline in low-skill wages. Hence, besides securing themselves a higher future wage growth, low-skill workers who switch to high-skill occupation also benefit the remaining lowskill workers. Although, the supply effect is important in the low-skill sector, the increase in supply of high-skill workers is asymptotically irrelevant, and we still have $g_{\infty}^{Y}=\psi g_{\infty}^{N}$. In fact, provided that an amended version of assumption 23 holds (with $\bar{H} \equiv \int_{0}^{1} \Gamma(j) d j=1$ replacing $H$ ), we can also extend the dynamic model of section 4 to this case. In particular, Proposition 3 remains unchanged (except for equation (24)).

Note, that as all changes in the stock of labor is driven by demand-side effects, wages and employment will move in the same direction. Extending our analysis of middle-skill workers to allow for switches between sector of employment could therefore reproduce the employment patterns of 'job polarization' in addition to 'wage polarization.

\section{Conclusion}

We construct an endogenous growth model of directed technical change with automation and horizontal innovation. Automation allows for the introduction of machines, which are complementary to high-skill workers, but replace low-skill workers. The model features a continuous shift of low-skill employment from recently automated firms to as of yet non-automated firms. For general processes of technological development low-skill wages must grow asymptotically,

\footnotetext{
${ }^{28}$ If $G_{t}$ tends towards 1 sufficiently fast such that $\lim _{t \rightarrow \infty}\left(1-G_{t}\right) N_{t}^{\frac{\psi(1-\mu)(\epsilon-1)}{1+(\epsilon-1) /(1-\alpha)}}$ is finite then $g_{\infty}^{w}=\frac{1+\alpha}{\alpha+\epsilon} g_{\infty}^{Y}$ for $\epsilon$ finite and $w_{t}$ is asymptotically finite (bounded below by $\widetilde{\varphi}^{-1}$ ) in the perfect substitute case.
} 
though at a lower rate than that of the economy. This result depends only on either some new products initially being non-automated or on machines and low-skill workers not being perfect substitutes in automated firms. In particular, neither our specific choice of innovation technology in Section 4, nor the exogenous nature of the stock of low-skill labor, nor the fact that all products are initially non-automated and can be automated with positive probability are crucial. Other assumptions, however, are important for the result. First, when machines and the consumption good are produced using the same technology, the constant real price of machines implies that the rising relative price of low-skill workers compared with machines must translate into increasing real wages. We show how a declining real price of machines can lead to asymptotically declining real wages for low-skill workers. In addition, an elasticity of substitution between products of more than 1 implies an asymptotically declining market share to non-automated products and thereby an asymptotically declining factor share to low-skill workers. Alternatively, a nested structure could allow an elasticity of substitution between some sectors, say services and manufacturing, of less than than one as explored in Acemoglu and Guerrieri (2008) and Autor and Dorn (2013). In addition new products could have an exogenous higher productivity (as in Lloyd-Ellis, 1999). Either specification could secure a higher growth rate for low-skill workers and they are each a topic for future research.

Moreover, our model delivers continuously rising inequality and a limited drop in the factor share of labor, both of which are consistent with recent empirical evidence. It further captures additional important features of income inequality such as the deceleration in income inequality the decade following the early 90s and the polarization of the wage distribution. Finally, automation and technological development are intrinsically linked to the international economy. Linking automation of production processes with international trade and offshoring is a fruitful path for future research.

\section{$9 \quad$ Appendix (to be added)}

\section{References}

Daron Acemoglu. Why do new technologies complement skills? directed technical change and wage inequality. Quarterly Journal of Economics, 113(4):1055-1089, 1998.

Daron Acemoglu. Directed technical change. The Review of Economic Studies, 69(4), 2002.

Daron Acemoglu. Equilibrium bias of technology. Econometrica, 75(5):1371-1409, 2007.

Daron Acemoglu and David Autor. Skills, Tasks and Technologies: Implications for Employment and Earnings, volume 4. Handbook of Labor Economics, Chapter 12, 2011.

Daron Acemoglu and Veronica Guerrieri. Capital deepening and nonbalanced economic growth. journal of political economy, 116(3):467-497, 2008.

Philippe Aghion and Peter Howitt. Research and development in the growth process. Journal of Economic Growth, 1(1), 1996.

Philippe Aghion and Peter Howitt. Endogenous Growth Theory. MIT Press, 1997. 
Philippe Aghion, Peter Howitt, and Giovanni L Violante. General purpose technology and wage inequality. Journal of Economic Growth, 7(4):315-45, December 2002.

David H. Autor and David Dorn. The growth of low skill service jobs and the polarization of the u.s. labor market. American Economic Review, 103(5):1553-1597, 2013.

David H. Autor, Frank Levy, and Richard J. Murnane. The skill content of recent technological change: An empirical exploration. The Quarterly Journal of Economics, 118(4):1279-1333, November 2003.

David H. Autor, Lawrence F. Katz, and Melissa S. Kearney. The polarization of the u.s. labor market. The American Economic Review, 96(2):189-194, 2006.

David H. Autor, Lawrence F. Katz, and Melissa S. Kearney. Trends in u.s. wage inequality: revising the revisionists. The Review of Economics and Statistics, 90(2):300-323, 2008.

Zsófia Bárány and Christian Siegel. Job polarization and structural change. Working Paper, 2013.

Ann Bartel, Casey Ichniowski, and Kathryn Shaw. How does information technology affect productivity? plant-level comparisons of product innovation, process improvement, and worker skills. Quarterly Journal of Economics, 2007.

Erik Brynjolfsson and Andrew McAfee. Race Against The Machine: How the Digital Revolution is Accelerating Innovation, Driving Productivity, and Irreversibly Transforming Employment and the Economy. Library of Congress Catalogin-in-Publication Data, 2011.

David Card and John E. DiNardo. Skill biased technological change and rising wage inequality: Some problems and puzzles. Journal of Labor Economics, 20(4), 2002.

F. Caselli. Technological revolutions. The American Economic Review, 89(1):78-102, 1999.

Mark Doms, Timothy Dunne, and Kenneth Troske. Workers, wages, and technology. The Quarterly Journal of Economics, 112(1):253-290, 1997.

Oded Galor and Omer Moav. Ability-biased technological transition, wage inequality, and economic growth. Quarterly Journal of Economics, 2000.

Claudia Goldin and Lawrence F. Katz. The Race Between Educaiton and Technology. Harvard University Press, 2008.

Maarten Goos and Alan Manning. Lousy and lovely jobs: The rising polarization of work in britain. The Review of Economics and Statistics, 89 (1):118-133, 2007.

Maarten Goos, Alan Manning, and Anna Salomons. Job polarization in europe. American Economic Review: Papers 83 Proceedings, 99 (2):58-63, 2009.

Andreas Hronstein, Per Krusell, and Giovanni Volante. The effects of technical change on labor market inequalities. Handbook of Economic Growth, 1(Part B - Chapter 20), 2005.

Loukas Karabarbounis and Brent Neiman. The global decline of the labor share. National bureau of economic research, (19136), 2013. 
Lawrence F. Katz and David Autor. Changes in the wage structure and earnings inequality. Handbook of Labor Economics, Chapter 26, 1999.

Lawrence F. Katz and Kevin M. Murphy. Changes in relative wages, 1963-1987: Supply and demand factors. The Quarterly Journal of Economics, 107(1):pp. 35-78, 1992.

Per Krussel, Lee E. Ohanian, Jose Victor Rios Rull, and Giovanni L. Violante. Capital-skill complementarity and inequality: a macroeconomic analysis. Econometrica, 68(5):1029-1053, September 2000.

Thomas Lemieux. Increasing residual wage inequality: Composition effects, noisy data, or rising demand forskill? The American Economic Review, 96(3):461-498, 2006.

Huw Lloyd-Ellis. Endogenous technological change and wage inequality. American Economic Review, 89(1):47-77, 1999.

Stephen Machin and John Van Reenen. Technology and changes in skill structure: Evidence from seven oecd countries. The Quarterly Journal of Economics, 113(4):1215-1244, 1998.

Francesca Mazzolari and Giuseppe Ragusa. Spill-overs from high-skill consumption to low-skill labor markets. The Review of Economics and Statistics, 95(1):74-86, 2013.

Richard R. Nelson and Edmund S. Phelps. Investment in humans, technological diffusion, and economic growth. The American Economic Review, 56(1/2):pp. 69-75, 1966.

William D. Nordhaus. Two centuries of productivity growth in computing. Journal of Economic History, 67(1):128-159, 2007.

Thomas Piketty and Gabriel Zucman. Capital is back: Wealth-income ratios in rich countries 1700-2010. 2013. URL http://piketty.pse.ens.fr/files/PikettyZucman2013WP.pdf.

Francisco Rodriguez and Arjun Jayadev. The declining labor share of income. Human Development Research Papers (2009 to present) HDRP-2010-36, Human Development Report Office (HDRO), United Nations Development Programme (UNDP), November 2010.

Paul M. Romer. Endogenous technological change. Journal of Political Economy, 98(5):pp. S71-S102, 1990. ISSN 00223808.

A. D. Roy. Some thoughts on the distribution of earnings. Oxford Economic Papers, 3(2):pp. 135-146, 1951. ISSN 00307653.

Jeffrey D. Sachs and Laurence J. Kotlikoff. Smart machines and long-term misery. NBER Working Papers 18629, National Bureau of Economic Research, Inc, 2012.

Alexandra Spitz-Oener. Technical change, job tasks, and rising educational demands: Looking outside the wage structure. Journal of Labor Economics, 24 (2):235-270, 2006.

Jan Tinbergen. Substitution of graduate by other labour*. Kyklos, 27(2):217-226, 1974.

Jan Tinbergen. Income Difference: Recent Research. North-Holland Publishing Company, Amsterdam, 1975. 
Timo Trimborn, Karl-Josef Koch, and Thomas M. Steger. Multimensional transitional dynamics: a simple numerical procedure. Macroeconomic Dynamics, 12(3), 2008. 